\title{
A PEDOLOGIA E A EVOLUÇÃO DAS PAISAGENS
}

\author{
Carlos Roberto ESPINDOLA
}

\begin{abstract}
RESUMO
Geomorfologia e pedologia surgiram em épocas distintas e com diferentes métodos de investigação das paisagens, instituindo a dualidade morfogênese-pedogênese. Às fases de evolução do relevo foram ajustados graus de desenvolvimento dos solos, estando normalmente aí envolvidas causas tectônicas e mudanças climáticas. Datações relativas das superfícies associavam critérios altimétricos a formas assumidas como testemunhas de antigos processos: lateritas, stone lines e paleossolos. A evolução da ciência mostrou que estas formas não precisam ser obrigatoriamente tomadas como $p a-$ leo, e que a própria autoevolução dos solos pode afetar o modelado superficial. Métodos sedimentológicos e datações absolutas associados às transformações dos horizontes pedológicos em topossequências possibilitam vislumbrar a instituição de uma morfopedogênese, ou uma pedomorfogênese, pela indissociabilidade do solo e do relevo na gênese das paisagens, posto que dependentes dos mesmos fatores de formação.
\end{abstract}

Palavras-chave: morfogênese, pedogênese, evolução da paisagem, paleoprocessos.

\begin{abstract}
Geomorphology and pedology were developed in different times and use different methods for landscape analysis, presenting a morphogenesis-pedogenesis duality approach. Each phase of relief evolution was related to a distinct soil development state. Tectonic processes and climatic changes are important factors to be considered in this study. The relative ages attributed to the associated surfaces were mainly based on laterite, stone lines and paleosol occurrences. New developments on science showed that particular processes related to soil development (autoevolution) can create new relief patterns, confirming that soil is a real factor for relief formation. Sedimentological and absolute dating methods associated with conventional studies of pedon transformation in toposequences made it possible to imagine a morphopedogenesis or pedomorphogenesis science, since soil and relief form an indissoluble unity affected by the same factors.
\end{abstract}

Keywords: morphogenesis, pedogenesis, landscape evolution, paleoprocesses

\section{INTRODUÇÃO}

Geomorfologia e Pedologia surgiram em épocas e lugares distintos, cada qual com o propósito de oferecer uma visão dinâmica das formações superficiais da litosfera a partir dos seus objetos de estudo: o relevo (morfogênese) e os solos (pedogênese), o que, em outras palavras, pode ser traduzido por evolução da paisagem.

A geomorfologia ocupou-se, sobretudo, dos processos superficiais responsáveis pela modelagem das superfícies ao longo do tempo geológico, tendo empreendido técnicas de minuciosa caracte- rização de vertentes e identificação de testemunhos de relevos antigos. Tornou-se paradigmática a representação das paisagens pelas fases do relevo juventude, maturidade e senilidade, a despeito das severas críticas sobre o caráter cíclico que Davis atribuiu a esse mecanismo.

A evolução do relevo em áreas desprovidas de movimentos tectônicos expressivos estaria subordinada a um nível de base a comandar os mecanismos de acumulação e remoção dos materiais das formações superficiais. Compartimentos com relevos suaves seriam aptos a acúmulos de espessos mantos de alteração e solos; ao contrário, rele- 
vos ondulados estariam sujeitos a descarnamentos erosivos e solos rasos. Mudanças climáticas, acompanhadas de modificações das coberturas vegetais, acarretariam novos direcionamentos nessa dinâmica. Raramente se atribuía ao solo a co-responsabilidade pelas modificações dos fluxos hídricos geradores das denudações.

O posterior surgimento da pedologia, com o russo Dokuchaev, já na segunda metade do século dezenove, subordinou a origem do solo à ação do relevo, junto aos demais fatores de formação, que JENNY (1941) eternizou numa clássica formulação matemática:

Solo $=\mathrm{f}$ (material de origem, relevo, clima, organismos, tempo).

O crescente interesse científico despertado pelo estudo sistematizado do solo propiciou uma diversificação dos distintos campos de atuação: fertilidade, adubação e nutrição vegetal, técnicas agrícolas conservacionistas e outros, ficando a denominação pedologia reservada ao campo da gênese, classificação e cartografia dos solos. Neste, o objeto de enfoque centrou-se no perfil - o "indivíduo solo", representativo de unidades cartográficas aparentemente homogêneas - unidades de mapeamento. Raramente se cogitava sobre as relações entre os perfis isolados e as unidades de mapeamento, como se estas tivessem vida própria e independência da paisagem que as continha.

Porém, a pedologia nacional passava ao largo das preocupações com as modificações das paisagens, embora o espírito acurado de Paul Vageler, do Instituto Agronômico de Campinas, conhecedor de áreas tropicais africanas, tivesse comentado que no decorrer de milênios até o mais pronunciado macro-relevo seria arrasado num peneplain (VAGELER 1953), assertiva inserida nos conhecimentos fornecidos por ERHART (1956) e TRICART (1968), com o binômio morfogênese-pedogênese. Passou praticamente despercebida pela comunidade científica brasileira uma linha metodológica em que FRANÇA (1968) associou a evolução de redes de drenagem à natureza dos solos, adaptando parâmetros até então adstritos à fotointerpretação aplicada a mecanismos geológicos.

A seu turno, a influência climática, há muito tempo ressaltada por WAYLAND (1933), veio ampliar os conhecimentos geomorfológicos, notadamente com PENCK (1953). Movimentos ascensionais de água no manto provocariam alteração do saprólito, rebaixamento da superfície original e a criação de etched plains, responsáveis por setores aplainados da paisagem. Os peneplanos e pediplanos assim gerados prestaram-se amplamente a ca- racterizações de superfícies geomorfológicas das paisagens tropicais, assim como a teoria da etchplanação para estudos detalhados (VITTE 2001).

Contudo, do ponto de vista pedológico entrevisto por Dokuchaev, os solos não foram usualmente inseridos naqueles modelos, mas apenas como mantos de alteração da crosta em evolução. Acredita-se que esteja aí envolvida, principalmente, uma questão de escala de observação (VIDAL-TORRADO et al. 2005), que nem sempre torna possível a inserção de diferentes unidades de solos. A geração de novas formas de modelado conduzidas pela pedogênese encontra substancioso suporte no conceito de solos como sistemas de transformação (MILLOT 1977, 1980), sob escalas detalhadas e técnicas analíticas especializadas, como a micromorfologia.

Certos descompassos entre ambas as ciências foram objeto de reflexões críticas em mesa redonda do VII Simpósio Nacional de Geomorfologia, em Recife (ESPINDOLA 2010) e constituem objeto de ponderação no presente trabalho, com o intuito de mostrar que solos e relevo agem solidariamente, o tempo todo, na modificação das paisagens terrestres, cujo passado no mundo intertropical é difícil de ser resgatado sem envolver uma grande dose de subjetividade.

\section{SUPERFÍCIES GEOMÓRFICAS E “LATERALIDADE” NOS PROCESSOS PEDOLÓGICOS}

É generalizada a premissa de que se não ocorrer nenhuma elevação das terras durante certo tempo, as vertentes tendem sempre a um aplainamento por efeitos erosivos, com modificações na expressividade dos mantos de alteração e do recobrimento vegetal condicionadas pelo comportamento do nível de base regional (BIROT 1968).

É indispensável levar em conta, nessa análise, mecanismos desencadeados por ações tectônicas, antigas e recentes, constituindo obra clássica nacional o trabalho de FREITAS (1951), sobre a tectônica moderna no nosso território. Inúmeras descrições dessa influência nos modelados são encontradas no Norte-Nordeste (SAADI 1993), no Centro-Sul (SOARES \& LANDIM 1976), ou, especificamente, na Bacia Sedimentar de Curitiba (SALAMUNI \& EBERT 1997). A sismicidade constitui uma manifestação tectônica em áreas de falhas, com manifestações sentidas em Manaus (AM), Belém (PA), São Luís (MA), Cuiabá (MT) e nos municípios paulistas de Ribeirão Preto, Presidente Prudente e Santos (BARTORELLI \& HARALYI 1998). 
No esquema davisiano de evolução do relevo, a uma fase de juventude, de vigorosa morfogênese, estariam associados solos jovens e rasos, que evoluiriam para a maturidade sob um relevo menos recortado, com mais equilíbrio entre erosão e acumulação de materiais (espessamento), até a senilidade, com a pedogênese refletindo solos num estádio máximo de desenvolvimento.

Critérios altimétricos sempre constituíram base fundamental para a caracterização de amplas superficies de aplainamento típicas das regiões intertropicais, acompanhados de registros particulares das posições cimeiras, relevos residuais, testemunhos, inselbergs ou monadnocks, na tentativa de se atribuir idades correlacionáveis aos respectivos tempos geológicos de sua instalação (datações relativas).

Esse procedimento foi amplamente empregado em superfícies tropicais, nos trabalhos pioneiros de DE MARTONNE (1943) e KING (1956) para o nosso território, tornando possível "balizar" eventos geomorfológicos na escala geológica do tempo. BARBOSA (1959) chegou a propor um quadro provisório das superfícies de erosão e aplainamento escalonadas para o Brasil começando no remoto Paleozóico Inferior (Paleoplano pré-Siluriano) e prosseguindo até o Holoceno (Ciclo Paraguaçu, de King).

Dentre as feições ou registros temporais empregados em associação a essas evidências paleogeográficas, as diversas formas lateríticas (couraças, carapaças, cangas, nódulos, concreções e cascalheiros), stone lines e horizontes escuros enterrados (sômbricos) muito se prestaram como evidências de paleoprocessos, ou seja, testemunhos de uma geração em condições pretéritas diferentes das atuais.

Para VAN DER VOORT (1950), verdadeiras lateritas apenas poderiam ser atribuídas a antigas condições climáticas, por requerem um tempo muito longo para a sua formação. Assim, corpos lateríticos e concreções constituiriam indícios bastante seguros de antiguidade, uma vez que os mecanismos de migração e acumulação dos quais resultam poderiam ser enquadrados, até mesmo, na categoria de processos geológicos (QUEIROZ NETO 1969).

Tornaram-se clássicas as pesquisas de BIGARELLA et al. (1965), caracterizando pedimentos (P) e pediplanos (Pd), usualmente envolvendo depósitos rudáceos alinhados em posições diversas nos mantos de alteração e solos, assumidos como paleopavimentos detríticos e indicativos de descontinuidades entre os materiais acima e abaixo posicionados. Essas stone lines poderiam faltar caso os materiais transportados fossem pobres em elementos grosseiros.
Uma notável expansão desses paleopavimentos foi atribuída ao Plio-Pleistoceno, de semi-aridez climática, o que chegou a assumir até certo caráter dogmático, base para datações relativas. Cangas limoníticas dos chapadões cristalinos de Goiás e de topos das serras de Minas Gerais foram tomadas como representantes de tais condições, cujas stone lines seriam oriundas do desmantelamento de depósitos lateríticos, que se juntariam aos materiais em trânsito nas encostas (AB'SÁBER 1957).

Com esses testemunhos paleoclimáticos, PENTEADO (1976) cartografou pedimentos e pediplanos da depressão periférica paulista, assim como AB'SÁBER (1972) já procedera na identificação de superfícies aplainadas de diversas regiões brasileiras, compondo uma "rede de neogênicas". Algumas poucas pesquisas correlatas levavam em conta a natureza dos solos associados, como as empreendidas por QUEIROZ NETO \& MODENESI (1973) e DIAS FERREIRA \& QUEIROZ NETO (1974), diminuindo a sujetividade de observações, por vezes, meramente especulativas.

A geomorfologia desenvolveu critérios minuciosos para caracterização das vertentes, em geral a partir de elementos essencialmente descritivos, porém, inicialmente, sem associá-los a atributos específicos dos solos ou dos mantos de alteração envolvidos, de modo que esses pudessem representar verdadeiros parâmetros indicativos das idades das superfícies e dos mantos de alteração, bem como das condições de deflúvio e infiltração, diretamente envolvidas no modelado.

Com a teoria da etchplanação, a geomorfologia incorporou, sobretudo, informes sobre as condições de intemperismo e velocidade das alterações em mantos superficiais, as quais afetam diretamente os solos e as formas topográficas. Datações absolutas também vieram acrescentar contribuições primordiais sobre a evolução das paisagens, diminuindo expressivamente a subjetividade das hipóteses que presidiam tais mecanismos, assunto esse que a pedologia nacional não explorou ainda devidamente.

O emprego da palinologia (MODENESI 1980) e da relação ${ }^{13} \mathrm{C} /{ }^{12} \mathrm{C}$ em solos de Campos do Jordão (MODENESI et al.1982) permitiu avançar no conhecimento das relações entre evolução das vertentes e distribuição da vegetação. Pesquisas experimentais foram efetuadas por MOEYERSONS (1981) na África Central, com medições de espessuras de terra erodida das colinas por rastejo. DE PLOEY (1985) estimou quantidades de materiais deslocados por esse mecanismo, em função do tempo, tendo pontificado que a evolução morfoge- 
nética é controlada essencialmente pela velocidade de erosão, enquanto o rastejo pode mostrar-se em equilíbrio com a velocidade de alteração.

Parâmetros da rede de drenagem associados a solos e relevo podem também proporcionar relevantes informações. A relação Infiltração/Deflúvio (I/D), empregada por BELCHER (1945) na interpretação de padrões aerofotogramétricos, é que, em última análise, governa os processos evolutivos das paisagens, conforme devidamente incorporado na mencionada tese de FRANÇA (1968), que deu início a uma série de investigações posteriores.

Uma eficiente drenagem funcional do manto de alteração, ou de determinado compartimento topográfico, faz que solos argilosos revelem padrões superficiais da rede de drenagem semelhantes aos dos arenosos, como constatado por DUNBAR (1950) em latossolos argilosos e latossolos de textura média. Para RAY (1963), o que governa os processos é a drenagem do perfil.

Evidências dessas assertivas foram constatadas em latossolos argilosos e solos arenosos espessos das antigas superfícies aplainadas, com as depressões fechadas associadas de Araras, Conchas e Anhembi, SP (ESPINDOLA \& GARCIA 1978, 1979). Aos seus padrões descritivos e parâmetros de drenagem superficial somaram-se caracterizações morfológicas, físicas, químicas e mineralógicas de perfis, possibilitando inferências adicionais sobre a evolução das paisagens (ESPINDOLA 1977, ESPINDOLA et al. 1983).

Uma esclarecedora evidência da influência do relevo, ou das condições topográficas, sobre a natureza e as propriedades dos solos ficou devidamente estampada com o emblemático conceito de catena, que colocava os solos de uma sequência topográfica como elos de uma corrente, cada um deles afetando o desenvolvimento do seu vizinho e o conjunto sendo influenciado pelas condições de drenagem interna (MILNE 1935).

A pormenorizada caracterização das alterações mineralógicas em catenas dos meios tropicais, empreendida por DELVIGNE (1965) na África, veio acrescentar importantes informes para o estudo dos mecanismos evolutivos das superfícies, notadamente sobre a gênese e transformação dos argilominerais e óxidos dos solos, até então muito circunscritos a domínios morfoclimáticos diferentes das nossas condições.

No final da década de 60 , começaram a surgir no Brasil pesquisas conjugando solos e relevo em sequências topográficas, com o trabalho pioneiro de QUEIROZ NETO (1969) na região de São Carlos, São Paulo. CARVALHO (1970) seguiu a mesma diretriz, acrescentando análises micromorfológicas, com a riqueza de informações que essa técnica já revelara em solos africanos (CHAUVEL 1972, BOCQUIER 1973). Discriminou em Ribeirão Preto, São Paulo, latossolos basálticos (LR) morfologicamente idênticos em superfícies de diferentes idades, principalmente a partir da natureza de suas argilas.

Analogamente, na zona basáltica do Médio Tietê, o Latossolo Vermelho rico em gibbsita $\left(\mathrm{LR}_{1}\right)$ ocorre em Jaú, numa antiga superfície, cujo desmantelamento gerou novos compartimentos topográficos, caracterizados nas vizinhas imediações de Barra Bonita. Nas porções mais entalhadas foram gerados Nitossolos (TE) e Neossolos litólicos (Li), e nas mais suaves um Latossolo Vermelho mais jovem $\left(\mathrm{LR}_{2}\right)$, praticamente desprovido de gibbsita (ESPINDOLA 1979). Com efeito, MONIZ \& JACKSON (1967) e LEMOS (1976) já haviam verificado que a quantidade de gibbsita oriunda da dessilicificação da caulinita pode constituir um bom índice para inferências dessa natureza.

Todavia, nem sempre os latossolos ocupam as superfícies mais antigas, como no caso anterior, embora sejam muito espessos e intemperizados (LEPSCH et al. 1977). Coberturas latossólicas microagregadas não devem ser obrigatoriamente interpretadas como correlativas de superfícies antigas, por não ocorrerem sistematicamente em posições cimeiras (QUEIROZ NETO 2000).

Não obstante em algumas pesquisas nacionais pedogênese e morfogênese tenham sido associadas em superfícies mais amplas do que catenas ou vertentes - como a de LEPSCH \& BUOL (1974), dentre as já citadas —, a visão da gênese nas publicações tradicionais de pedologia ficou praticamente restrita à mineralogia das argilas em perfis verticais isolados, daí se inferindo mecanismos de evolução pedogenética. Sob esta óptica metodológica, uma quantidade substancial de publicações foi produzida nos nossos diferentes domínios geográficos.

De posse desses dados de mineralogia das argilas e de informações documentais sobre as superfícies de aplainamento, feições paleo e datações relativas, PÉDRO \& VOLKOFF (1984) produziram um mapa generalizado da cronologia das principais coberturas pedológicas brasileiras.

Com o acréscimo do registro de ocorrências de solos, com suas designações populares, MABESOONE \& LOBO (1980) estabeleceram um esboço das superfícies aplainadas de uma vasta extensão do Nordeste brasileiro, cuja sequência geocronológica inicia-se na Superficie Sulamericana, 
do Oligoceno (com o solo senil Camaragibe e a Formação Campos Novos), e termina na Superficie Paraguaçu, do Pleistoceno ao Holoceno antigo (solo jovem Potengi, areias brancas e Formação Macaíba), com outras intermediárias.

\section{ESTUDOS PIONEIROS SOBRE A ORIGEM E DESENVOLVIMENTO DOS SOLOS}

FELLER et al. (2006) elaboraram um minucioso inventário a respeito de estudos científicos do solo antes da existência de uma ciência específica para tal finalidade. Em publicação anterior, FELLER et al. (2003) reproduziram ilustrações de cortes arqueológicos de escavações romanas de Abinger, efetuadas por Darwin em 1881, mostrando uma sucessão de camadas A-B-C-D e suas respectivas constituições, e até mesmo um alinhamento de fragmentos, possivelmente análogo ao que viria a ser referido muito tempo depois como stone line.

A concepção do solo como um corpo natural em evolução na paisagem surgiu no vácuo da bombástica teoria darwinista de evolução das espécies. O russo Dokuchaev considerou-o originário de uma rocha-mãe (posteriormente, um material de origem) situada em determinada posição do relevo, sujeita à ação do clima e dos organismos ao longo do tempo. Sua publicação sobre os solos negros das estepes russas - o Chernozém (DOKUCHAEV 1893) representa um marco histórico.

Estavam aí esboçados os fatores de formação dos solos, cuja ação integrada desencadearia processos internos complexos, mediante distintas combinações entre mecanismos de translocações (seletivas e não seletivas), transformações dos constituintes gerados pelas alterações mineralógicas, adições ao manto de alteração e perdas subsuperficiais, muito bem exploradas em SIMONSON (1959). Aos processos de formação gerados pelas intensidades variáveis de cada mecanismo interativo cada escola pedológica atribuiu diferentes denominações: podzolização, ferralitização, latossolização, gleização etc. (DUCHAUFOUR 1968).

Sob a ação de agentes do intemperismo, constituintes orgânicos (vegetais e animais) depositados numa superfície de rochas ou sedimentos coadjuvam uma série de modificações físicas, químicas e mineralógicas. Uma fragmentação é responsável pela geração de componentes mais finos (areias, siltes e argilas) aglutinados (agregados), promovendo uma expansão volumétrica do sistema e prenunciando o início da formação de uma camada diferenciada. Para VILENSKI (1937), a formação do solo começa já no momento de instalação dos organismos sobre as rochas, aí se desenvolvendo um processo biológico.

Este solo em formação é diferenciado da alterita ou substrato em vias de alteração por ser menos rico em fragmentos e minerais primários. Nas rochas básicas essa passagem pode ser brusca, pela fragilidade de seus constituintes aos agentes intempéricos. O sobreveniente espessamento do conjunto, com um progressivo decréscimo de minerais alteráveis, gera horizontes mais ricos em minerais secundários e/ou minerais muito resistentes às alterações. Em superfície, a constante deposição, sobretudo a orgânica (viva e morta), provoca escurecimento do horizonte diretamente em contato com a atmosfera.

À sucessão vertical de materiais gerados deu-se o nome de perfil de solo, cujas camadas genéticas justapostas acompanham a superfície estabelecendo uma certa horizontalidade - os horizontes. Um perfil bem desenvolvido seria representado pela sequência vertical A-B-C, cujo estudo sistemático garantiu à pedologia a condição de ciência autônoma para tratar do solo.

Segundo TANDARICH et al. (2002), nos primórdios da pedologia norte-americana o perfil de solo ainda era representado sem os horizontes; mesmo a denominação perfil foi formalizada apenas em 1924, mediante uma circular do órgão oficial que tratava desses assuntos, sacramentada na representação dos solos brunos do nordeste (KRUSEKOPF 1925) e em solos da Austrália (SHAW 1925). Atribui-se a KELLOGG (1936) a denominação solum para as camadas acima do horizonte $\mathrm{C}(\mathrm{A}+\mathrm{B})$.

Uma vertiginosa aplicação dos conhecimentos em química dos solos ocorreu com a deflagração da teoria mineralista da nutrição de plantas (LIEBIG 1840), com forte apoio do meio de produção agrícola, e, sobretudo, da indústria de fertilizantes. O conhecimento sobre os solos foi se ampliando, aplicado aos vários ramos das ciências básicas tradicionais, o que propiciou uma ciência do solo com vários ramos: física do solo, fertilidade do solo, gênese e classificação de solos etc. A denominação pedologia acabou se restringindo a este último campo, com grande aplicação no mapeamento de solos.

No clima temperado com inverno rígido em que a pedologia foi concebida, o perfil A-B-C típico gerado era o do Podzol, muito ácido, com um $\mathrm{B}$ em arranjamentos poliédricos, enriquecido em colóides minerais e orgânicos por eluviação-iluviação decorrente de decomposições minerais produzidas por ácidos orgânicos enérgicos no A (fer- 
rólise). Corresponde atualmente ao Espodossolo, com o horizonte diagnóstico - $B$ espódico, outrora referido por Bhir (h=húmus; ir=ferro), com elevado incremento de argilas iluviais, revestimentos escuros de componentes orgânicos e elevada acidez (baixos valores de $\mathrm{pH}$ ).

No mundo intertropical foram identificadas vastas extensões de solos com perfis morfologicamente semelhantes aos Podzóis, porém com atributos químicos e mineralógicos muito diferentes, por terem sido gerados sob condições normais de $\mathrm{pH}$. Aos seus horizontes poliédricos deu-se o nome $B$ textural $-B t$, formado por uma pseudo-podzolização (ZONN 1978) ou lessivage (DUCHAUFOUR \& LELONG 1967), caracterizada pelo arraste mecânico de partículas finas, com a presença comum de cerosidade ou cutãs (clay skins) revestindo agregados (shiny peds).

Estes perfis com Bt passaram a representar solos referidos por Podzólicos ou Podzolizados (BRASIL 1960), denominação empregada em alguns países para solos sob podzolização. Apenas muitos anos depois, passaram a ser denominados Argissolos e Luvissolos (EMBRAPA 2006), embora mantidas as tradicionais siglas PV ou PVA (Podzólico Vermelho-Amarelo) nas legendas dos mapas pedológicos. $\mathrm{O}$ horizonte $\mathrm{A}_{2}$ ou A2, de máxima perda, passou a ser designado horizonte $E$, embora mantido como Ae na classificação canadense, sem descaracterizar o tradicional sistema A-B-C (CANADÁ 1987).

Mais disseminados no mundo tropical, mais espessos e intemperizados, são os solos englobados inicialmente sob a designação Lateríticos, como os Laterite soils (BALDWIN et al. 1938), com horizontes B subsuperficiais predominantemente microgranulares e irrelevante translocação de colóides, pela condição floculada das argilas, praticamente destituídos de cerosidade e com passagens graduais ou difusas de uma camada a outra.

Para dissociá-los da suposta presença de laterita, que a denominação solo Laterítico sugeria, aquela designação foi substituída por Latosol (KELLOGG 1948) e, por extensão, seu horizonte característico passou a ser o $B$ latossólico dos nossos Latosols (BRASIL 1960), termo posteriormente aportuguesado para Latossolos. Para condições correspondentes, os norteamericanos empregaram o designativo oxic horizon - Bw (USA 1994), indicativo de um elevado grau de intemperismo $(\mathrm{w}=$ weathering $)$.

Alguns especialistas reforçaram a preservação do designativo $\mathrm{B}$ apenas para horizontes de acúmulo. Assim, acúmulos de argilas e cálcio no B caracterizariam horizontes $\mathrm{Bt}$ e Bca, como apontado por LAATSH (1938), o que restringiria o aplicativo B a horizontes como o B latossólico.
Por essas razões KUBIENA (1952) chegou a representar como $(B)$ o horizonte típico dos Latossolos, além de ter mencionado perfis com horizontes B e (B) justapostos, o que pode ser interpretado como um horizonte poliédrico sobre um microagregado, como é comum ocorrer em Argissolos, Luvissolos (Bt-Bw) e Nitossolos (Bni-Bw).

Essa antiga preocupação em descartar o emprego de horizonte B para os Latossolos foi ressuscitada por RUELLAN \& DOSSO (1993), com a proposição de um bizarro horizonte sesquioxídico caulinítico - Sk, em contato direto com a rocha-mãe, ou, mais comumente, com o horizonte de alteração C. Esse cuidado induz à suposição da passagem direta do material em alteração para o horizonte microagregado.

Porém, a mesma representação $(B)$ fora também empregada como horizonte $B$ incipiente nos primeiros levantamentos de solos de nossos estados federativos. No Estado de São Paulo, foram descritas unidades de mapeamento de solos arenosos espessos e muito intemperizados como Regosols intergrades (BRASIL 1960), denominação posteriormente substituída por Areias Quartzosas (CAMARGO et al. 1987), com aquele horizonte passando a ser (indevidamente) representado por $C$.

Posteriormente, o significado explícito de $B$ incipiente - Bi passou a identificar um horizonte contendo minerais alteráveis, ou elevado teor de silte, características típicas de moderado grau de desenvolvimento, como o cambic horizon dos Cambissolos da classificação norteamericana. Nestes, não há exigências quanto ao tipo de estrutura, podendo, ou não, conter cerosidade, sugerindo uma evolução progressiva tanto em direção a um solo com $\mathrm{B}$ poliédrico como a um com B microgranular.

A denominação Bni-horizonte nítico surgiu para representar uma estrutura também poliédrica no $\mathrm{B}$, mas em perfis sem gradientes texturais significantes e com abundante cerosidade, como o solo de rochas básicas anteriormente denominado Terra Roxa Estruturada. Instituiu-se, assim, a classe dos Nitossolos (EMBRAPA 2006).

Não obstante esses aprimoramentos taxonômi$\cos$, o horizonte $C$ continuou a manter uma insólita concepção dupla, até mesmo contraditória, já apontada reiteradas vezes (ESPINDOLA et al. 1980, ESPINDOLA 2008): a) pouco desenvolvido, com fragmentos de rocha e/ou minerais em franca alteração; b) camada espessa, muito intemperizada, abaixo do horizonte A, com menos de $15 \%$ de argila, como nas Areias Quartzosas, que passaram a ser denominados Neossolos Quartzarênicos, da mesma classe dos Litossolos e dos Aluviais (EMBRAPA 2006). 
Essa contradição cria um descompasso na interpretação das relações pedogênese-morfogênese, pois os Neossolos Quartzarênicos, assim como os Latossolos, ocupam, quase invariavelmente, posições cimeiras de antigas superfícies aplainadas. São muito espessos e intemperizados (ESPINDOLA \& GARCIA 1979, ESPINDOLA \& CARVALHO 1986), contrariando a assertiva de AZEVEDO \& DALMOLIN (2004) de que os Neossolos estão "em processo de formação"; mais fácil é admiti-los como senis, em processo de desmantelamento das superfícies a que eles se associam.

O fato de possuírem menos de $15 \%$ de argila revela-se inconsistente para justificar um solo como pouco desenvolvido. Teria sido mais coerente resgatar o limite de $8 \%$, outrora utilizado para atribuir essa qualificação, que confere um aspecto desagregado ou desestruturado (grãos simples), como muitos depósitos aluvionares ou formações dunares de costas litorâneas. Além disso, a estrutura não mais constitui atributo diagnóstico para classes de solos, sendo até admitidos horizontes Bw com estruturas em blocos ou coesas (EMBRAPA 2006).

O levantamento de solos do território paulista (BRASIL 1960) reunia, nas categorias mais elevadas do sistema adotado: a) Solos com B textural; b) Solos com B latossólico; c) Solos Hidromórficos; d) Solos Pouco Desenvolvidos. Propugnava a seguinte evolução: Rocha $\rightarrow$ Litossolo $\rightarrow$ Solo com B textural $\rightarrow$ Solo com B latossólico. As categorias a e b reuniam os solos bem desenvolvidos; c, os solos moderadamente desenvolvidos e d, os pouco desenvolvidos.

Difícil é encaixar nessa evolução progressiva os solos arenosos espessos, razão pela qual a literatura registra denominações escapistas, como: "Latossolos arenosos" - Sand Latosols (MARQUES 1958), ou "solos com B latossólico arenosos" (COUTARD et al. 1983). LORANDI et al. (1985) representaram com horizontes (B) Areias Quartzosas de posições elevadas de antigas superfícies aplainadas, e OLIVEIRA \& PRADO (1984) as correlacionaram aos solos Ferralíticos arenosos da classificação francesa, reconhecidamente bem desenvolvidos.

A associação dessas categorias com o relevo era assim referida, como predominante: a) solos com Bt, em relevo ondulado; b) solos com B latossólico, em relevo suave-ondulado; c) solos hidromórficos (gleizados), em relevo plano; d) solos pouco desenvolvidos - Aluviais, em relevo plano e Litossolos, em fortemente ondulado. Generalizações aproximadas dessas associações para a Mantiqueira Norte-Ocidental são encontradas em
QUEIROZ NETO et al. (1981). RESENDE et al. (1988) agregam também as condições de drenagem interna apresentadas por esses solos.

\section{A COMPLEXIDADE DO MATERIAL DE ORIGEM NO MUNDO TROPICAL}

A pedologia emergiu como ciência na Rússia, onde os solos provêm do curto período de intemperismo posterior à última glaciação, com o substrato identificado como rocha-mãe. Essa denominação foi substituída por material de origem, de maior amplitude, passível de transporte e redeposição já com determinado grau de alteração.

Contudo, em tempos não distantes, descrições morfológicas em nossos manuais de campo apregoavam ainda a prospecção de perfis "até uma profundidade que atingisse o material de origem do solo" (LEMOS \& SANTOS 1976), numa alusão a um corpo rígido como a rocha, ou pouco alterado, pressupostamente in situ

A designação lateríticos para os solos das regiões tropicais residia na expressiva quantidade de minerais residuais do intemperismo, como o quartzo e sesquióxidos, componentes usuais das lateritas, em suas diversas formas e denominações: nódulos, concreções, pisolitos, piçarras, cangas, couraças e carapaças. Stone lines também são frequentemente constituídas por esses componentes e por seixos de constituições diversas.

Idades avançadas foram atribuídas a essas feições e solos associados, prestando-se até a correlações em datações relativas das superfícies onde ocorrem, em contraste com as formações superficiais das regiões temperadas, com gênese relacionada a materiais frescos da última glaciação quaternária. QUEIROZ NETO (1969) ponderou que no meio tropical úmido esses processos pedologicamente antigos, envolvendo lateritas e concreções, poderiam ser até enquadrados na categoria de processos geológicos, o que posteriormente reviu e contestou.

Para essas regiões livres das glaciações, com alternâncias de períodos chuvosos e secos, passou-se a dar mais importância à natureza transportada dos materiais de origem, conferindo à pedogênese tropical uma real complexidade. Características múltiplas poderiam ser adicionadas a cada nova condição climática, com sobreposições de processos, apagando determinadas feições e deixando testemunhos de outras (características paleo).

Para o continente sulamericano, BENNEMA et al. (1962) consideraram a possibilidade de retrabalhamentos de dimensões territoriais, que envolviam a 
cordilheira andina e a vasta planície amazônica, afetando a formação e a natureza dos nossos solos, cujos processos genéticos poderiam recuar ao Mesozóico.

Já muito antes, MORAES RÊGO (1945) distinguira solos autóctonos e alotóctonos (sic), em conformidade com suas formações in situ ou transportada pelo vento ou pela chuva. Para RUELLAN (1950), os solos eram derivados da desagregação e decomposição das rochas, sujeitos a mecanismos eluviais, coluviais ou aluviais. A designação eluviais foi empregada para designar materiais produzidos in loco, que aquele pesquisador reconhecia da semelhança entre o aspecto do solo formado e a rocha granítica associada.

Em pedogênese, chegou a se tornar redundante a generalização de que os nossos solos não se formam diretamente às custas de um material in situ. Segundo TRICART (1968), eles provêm de formações superficiais, alteritas, depósitos de vertentes, aluviões, colúvios, acumulações eólicas etc, de sorte que a rocha-mãe, na maior parte dos casos, pertence mais ao meio geomorfológico do que, propriamente, ao meio geológico. Acrescenta que em morfogênese são requeridos conhecimentos sobre fenômenos de transferência de matéria, migração de íons, deslocamento de detritos ao longo das vertentes e outros, para que a geomorfologia não permaneça no estágio da descrição e explicação imaginativa da qual W. M. Davis foi a expressão mais avançada.

Para MONIZ et al. (1982), a falta de conhecimento sobre o material de origem dificulta a tarefa de decifrar a gênese dos nossos solos, sendo muito difícil, senão impossível, desvendar esse material em um perfil formado em ciclos pedogenéticos sobrepostos. Reafirma-se a menção de GUPTA (1993), de que os trópicos constituem um depósito preenchido por maravilhas geomorfológicas aguardando estudos apropriados e especializados.

QUEIROZ NETO (1974) chegou a propor uma tipologia dos materiais de origem dos solos do Brasil de Sudeste, pela qual OLIVEIRA \& MENCK (1984) atribuíram a formação de Latossolos a materiais poligenéticos, com perfis complexos, por exibirem linhas de seixos e cascalheiros. Igualmente, descontinuidades erosivas e materiais retrabalhados foram atribuídos por QUEIROZ NETO \& MODENESI (1973) a stone lines, horizontes de cascalhos miúdos e paleohorizontes Bt sobrepondo horizontes Bt e Bw.

Com o propósito de uma classificação de ampla aplicação ao mundo tropical, pesquisadores da antiga ORSTOM (França) elaboraram um projeto de classificação taxonômica, infelizmente não implantado por alegação de outras prioridades, mas que chegou a ser divulgado em meios restritos. Distinguiam-se, neste, duas categorias de materiais de origem: a) alterito, formado no local, a partir da rocha subjacente e b) pedolito, formado alhures e redepositado por agentes mobilizadores (FAUCK et al. 1979).

Alguns critérios tradicionais empregados para estabelecer a aloctonia ou a autoctonia dos materiais foram as frações e subfrações granulométricas dos solos, a distribuição de minerais resistentes e relações entre seus teores no perfil, a morfoscopia das areias, as análises químicas totais e outras. Fator complicador costuma ser a ocorrência de minerais estranhos ao substrato, detectados nos minerais pesados das areias dos horizontes (MARCONI 1973), ou as diferentes formas de quartzo (ESPINDOLA et al. 1981 b).

Em descrições morfológicas de perfis de solos, linhas de seixos, pedras, cascalhos, ou, genericamente, stone lines, representam a ocorrência inconteste de descontinuidades entre os horizontes pedológicos, mesmo que haja uma semelhança marcante entre eles (OLIVEIRA et al. 1987). Por isso, é usual encontrar descrições de perfis assinalando stone lines com algarismos antepostos à designação dos horizontes abaixo de onde elas ocorrem.

Hipóteses sobre a gênese dessa descontinuidade são fartamente encontradas na literatura, algumas advogando a formação in situ, outras invocando retrabalhamentos a distâncias variadas, remanejamentos mecânicos localizados (transportes ascensionais pela fauna edáfica) e possibilidades conjugadas. Para TRICART (1959), não existe senão uma longínqua relação entre a composição petrográfica de um cascalheiro e a natureza dos afloramentos que a alimentaram.

As diversas possibilidades de formação das stone lines, desde os primórdios de sua menção científica, então referidas como pebble-bands (KAY 1931), ou landslides (SHARPE 1938), foram esmiuçadas em ESPINDOLA (2008), lembrando que há muito tempo, no oeste paulista, WASHBURNE (1930) já as havia referido como seixos de idade terciária sobrepostos por sedimentos argilo-arenosos.

Retomadas críticas surgiram à medida que novas pesquisas mostravam determinadas evidências. Assim é, que QUEIROZ NETO (2000), antes defensor da aloctonia das stone lines, passou a atribuir-lhes uma gênese autóctone, principalmente com base nas pesquisas geradas sob a óptica da análise estrutural da cobertura pedológica (BOULET et al.1990). 
A tese de MIKLÓS (1992) postulou uma ação homogeneizadora exercida pela fauna edáfica nas camadas separadas pelas stone lines, após ter fotografado a ação de cupins sobre um basalto em alteração na base de um perfil, com a produção de microagregados atribuíveis à estrutura do latossolo superposto. Essas ações biológicas poderiam gerar também horizontes escuros subsuperficiais (sômbricos), descartando a consensual concepção de paleossolos enterrados a eles atribuída.
Contudo, em projeto de A.A.W. Miklós, para orientação em programa de mestrado, MARTINS (2007) caracterizou um pedon sobre quartzo-xisto com um cupinzeiro extinto adjunto, tendo confirmado observações de ESCHENBRENNER (1986) e de SCHAEFFER (2001), de que câmaras, canais biológicos e vazios de raízes mortas são preenchidos por agregados granulares elaborados pelos cupins apenas em sítios preferenciais de umidade, incluindo a alterita. Porém, a estrutura do conjunto, em blocos subangulares, ocupa quase todo o perfil (Figura 1).

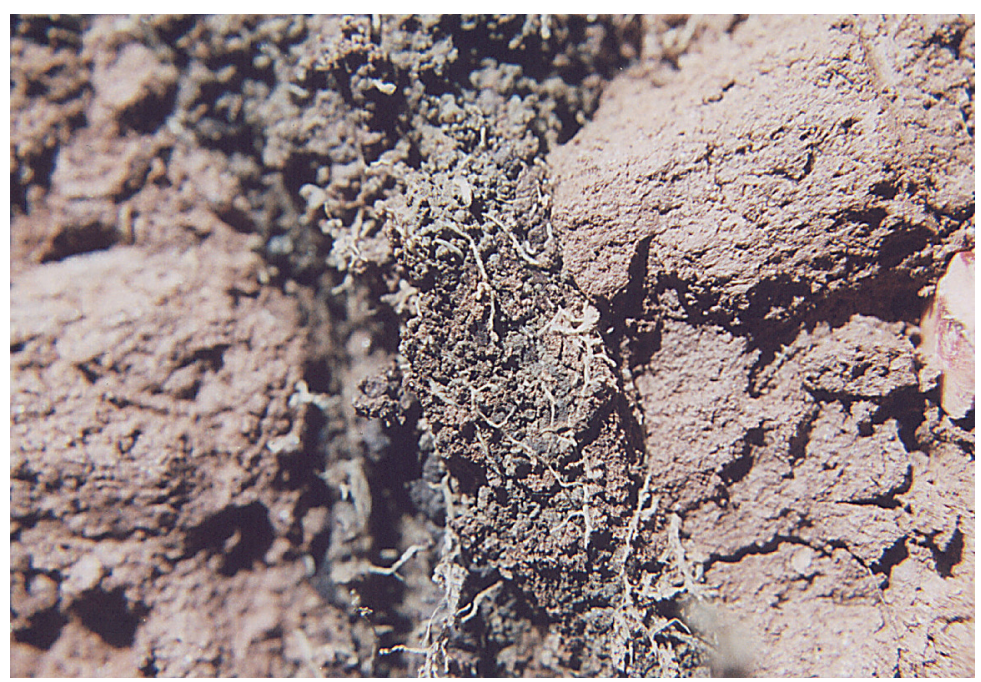

FIGURA 1 - Solo de estruturação poliédrica com sítios microgranulares produzidos por cupins (Foto cedida por G. M. Martins)

Microagregados vermelhos contendo grumos bruno escuros de coprólitos de minhocas indicaram que a desintegração do edifício, por chuvas e formigas, acarreta uma integração dos microagregados ao solo, confirmando observações de JUNGERIUS et al. (1999). SHAEFFER (2001) chegou a atribuir a estrutura microgranular de latossolos brasileiros à prolongada ação biológica pós-desmonte desses edifícios. Como reforço, referiu-se à sintonia entre a geração dos solos e a ação biológica, sendo o microagregado um produto gerado ao longo do tempo. Essa hipótese ora não se consubstancia, pois haveria necessidade de todo o conjunto poliédrico $(\mathrm{Bt})$ transformar-se em microagregado, neste caso, sem a ação dos cupins, já inexistentes no local.

AB'SÁBER (1962) já contestara veementemente uma ação tão ampla de cupins a ponto de gerar stone lines e responder pelas suas espessuras, continuidade espacial e densidade na acomodação entre os seixos; além disso, mesmo com transportes ascensionais de grandes volumes, haveria impossibilidade de recobrimento de toda uma vertente.

Uma nova revisão sobre a origem das stone $l i$ nes foi procedida por HIRUMA (2007), incluindo referências a análises geoquímicas de multielementos, empregando terras raras e elementos químicos índices de baixíssima mobilidade - Th, Sc e Hf (BRO$\mathrm{WN}$ et al. 2004), bem como isótopos cosmogênicos (COCKBURN \& SUMMERFIELD 2004). A partir do isótopo cosmogênico ${ }^{10} \mathrm{Be}$, BRAUCHER et al. $(1998,2004)$ constataram que a origem tanto pode ser autóctone como alóctone, não sendo ambas excludentes, podendo até se complementarem, mas considerou oportuna uma elucidação multidisciplinar, envolvendo pedólogos, geomorfólogos e biólogos.

SANTOS et al. (2010) também utilizaram o isótopo cosmogênico ${ }^{10} \mathrm{Be}$, dando porem mais crédito à autoctonia, com geração de detritos garantida por veios de quartzo ou fragmentos de crostas lateríticas, mas sem afastarem a possibilidade de recobrimentos eólicos, coluvionamentos, inver- 
sões de materiais por processos sucessivos de remoção e deposição. Sismicidade poderia favorecer acúmulos localizados de fragmentos (THOMAS 1994) e pressões elevadas de água nos poros poderiam causar descenso de elementos grosseiros (MOEYERSONS 1987).

Para solos sobre rochas básicas seria plausível atribuir as stone lines a produtos do desmantelamento de lateritas, como entrevisto por BOCQUIER et al. (1984), ao comentarem que os resíduos grosseiros acima e abaixo de stone lines podem ter origens comuns, ligadas à degradação de couraças ferruginosas in situ. Outra fonte imaginável seriam os arenitos eólicos adjuntos à Formação Serra Geral, por vezes até dispostos na forma de trapps, colocando ambas as rochas em contato direto.

Admitida a aloctonia, os solos acima dos alinhamentos seriam provenientes de distâncias variáveis, de materiais semelhantes ou diferentes daquele que, supostamente, teriam dado origem ao conjunto inferior. Contudo, na grande maioria dos casos, os horizontes pedológicos acima e abaixo das stone lines são muito semelhantes em seus atributos morfológicos, físicos, químicos e mineralógicos, o que alimenta uma defesa pró-autoctonia, coadjuvada pela reconhecida homogeneização praticada por cupins.

Solos sobre rochas básicas, com ou sem stone lines, revelam sempre determinadas ocorrências que denunciam a natureza do substrato, tais como a presença expressiva de magnetita e ilmenita, mesmo que os alinhamentos estejam a mais de 20 metros de profundidade e ocorram minerais típicos de outras rochas ou sedimentos, conforme constatado por MELFI et al. (1966) em solos de diabásio. Entretanto, minerais alogênicos podem ter se imiscuído nos pedons durante o seu espessamento, com deposições sujeitas às condições topográficas e ao vigor dos transportes vigentes nas diferentes ocasiões (ESPINDOLA 2008, 2009).

Aportes dessa natureza já haviam sido apontados por AGAFONOFF (1932) em solos diabásicos de Piracicaba e Campinas, ao constatar quartzos com feições que denunciavam transportes por água e vento. Também TRICART (1968) menciona que variações volumétricas provocadas pelas variações de umidade, especialmente nos horizontes superficiais, provocam reptações ao longo das vertentes, facultando o ingresso de elementos alógenos, os quais podem misturar-se a produtos de ações biológicas, inclusive detritos resistentes de rochas provenientes da parte mais alta das vertentes. Acrescenta que a caracterização de minerais pesados poderia indicar essa contribuição.
Distribuição muito irregular desses minerais alógenos deve configurar descontinuidades apenas quando ocorrem em concentrações localizadas, por vezes ligadas a mudanças texturais abruptas ou a outras feições anômalas do perfil. Considerando que acumulações e transformações tornam-se mais superficiais à medida que o solo se espessa (BOCQUIER 1973), esses alógenos podem estar ausentes em certos horizontes ou em distintos perfis de um mesmo solo. Reais discrepâncias nas relações entre minerais índices (zircão/ turmalina, por exemplo) devem ser interpretadas pelo emprego de probabilidades estatísticas nas análises sedimentológicas (SUGUIO 2003).

Com propósito cartográfico-taxonômico, OLIVEIRA et al. (1987) estudaram a morfoscopia, mineralogia e granulometria das areias de solos de uma mesma classe taxonômica, porém em posições litoestratigráficas distintas, incluindo stone lines. Distribuições diferenciadas das areias nos perfis, em seus diâmetros médios, esfericidade e arredondamento, apontaram diversidade no transporte e sedimentação, a revelarem uma natureza poligenética dos solos.

Se por algum mecanismo incontestável se confirmar a aloctonia, reforça-se a ação de homogeneização das camadas dos perfis exercida pela fauna edáfica, processo entrevisto como responsável pela transformação de um Bt em um Bw (BRASIL 1960). Esta via de evolução progressiva foi pouco explorada pela micromorfologia, cujas pesquisas enfatizaram a via inversa, ou seja, de uma evolução regressiva - transformação do Bw em Bt ou Bni.

Calcado na autoctonia dos materiais de origem, no Estado de São Paulo, as unidades de mapeamento pedológico foram estabelecidas sempre em conformidade com as respectivas formações geológicas. Porém, na área sob influência do Reservatório de Furnas, reconheceu-se que nem mesmo os jovens litossolos estavam livres de descontinuidades entre o horizonte superficial e a rocha abaixo (BRASIL 1962). É porém incontestável que a pedogênese é fortemente influenciada pela natureza do substrato.

Sob condições particulares, como efeitos de altitude ou hidromorfismo, podem ser gerados horizontes orgânicos, chernozêmicos, turfosos, ou solos como a "terra preto de índio", ricos em fósforo. Cinzas vulcânicas geram Andossolos, a ponto de, na fria Islândia, a rocha-substrato de solos limosos de prados pouco interferir sobre a adição que essas cinzas conferem (AUBERT \& CAILLEUX 1962).

A superimposição de um fator de formação sobre os demais levou KALPAGÉ (1976) a ressaltá-la com denominações indicativas. Forte domínio do material de origem caracterizaria um fator litogêni- 
co, como no caso das cinzas nos Andossolos, argilas expansivas nos Vertissolos e carbonatos nas Rendzinas. O fator topogenico mostraria forte influência do relevo ou das condições topográficas. Atribuiu primordialmente ao fator climatogênico a ação de ferralitização (laterização) ou podzolização.

De certa forma, essa preocupação já estava implícita no início da pedologia, na lei da zonalidade, apropriada àquelas condições bioclimáticas, mas de difícil adaptação para as tropicais, onde atuaram paleoclimas. Exemplo típico é a ocorrência no nordeste semiárido brasileiro de latossolos idênticos aos de outras regiões úmidas (NUNES \& ESPINDOLA 1993). Por razões dessa natureza, ZONN (1978) ressaltou a importância de se levar em conta as características zonais e subzonais dos solos para determinar seus padrões de distribuição geográfica em regiões bioclimáticas específicas. Verifica-se, pois, um caráter ambíguo na aplicação do termo zonalidade.

A forte influência exercida pelo substrato nos perfis pedológicos sob condições normais de boa drenagem foi assinalada por QUEIROZ NETO (2008), em defesa da autoctonia do material de origem e das stone lines; a maior parte dos solos seria proveniente da alteração dos respectivos embasamentos, reformulando proposições antigas em favor da aloctonia.

Antigos trabalhos atribuíam origens distintas às "terras roxas": a partir de basaltos vesiculares, derivados de diabásio e da alteração de gabros (GUTMANS 1943). Para solos análogos, PAIVA NETTO et al. (1951) distinguiram solos cauliníticos, da decomposição antiga do diabásio, e solos ricos em gibbsita, do intemperismo atual. Encontram-se aí insinuadas superfícies geomórficas de diferentes idades, como posteriormente evidenciado por CARVALHO (1970) em solos basálticos paulistas.

Provavelmente, embuídos da idéia de autoctonia, TOLEDO et al. (2000), na difundida obra "Decifrando a Terra", representam o pedon a partir diretamente da rocha fresca sobre a qual se instalam saprolito e solum, constituindo o regolito (manto de alteração), com a explicação de que o saprolito é sujeito a reorganizações promovidas por processos pedogenéticos que dão origem ao solo.

MELFI \& MONTES (2008) reforçam que a pedogênese se dá pela transformação do saprolito (material friável, móvel, anidro, mineral e abiótico) em um corpo organizado, friável, poroso, hidratado, mineral+orgânico, capaz de assegurar a alimentação mineral dos organismos vivos autotróficos e, em particular, dos vegetais superiores. Retomam o conceito de horizonte $\mathrm{B}$ como de máxima iluviação dos solos bem desenvolvidos (perfis A-B-C), sem cogitarem na existência do B latossólico.

Mesmo que o substrato se identifique como material de origem do solo, muita complexidade ainda persiste no entendimento da pedogênese tropical, uma vez que à intensidade do intemperismo associa-se o prolongado tempo de pedogênese, com irrefutáveis mecanismos operantes nos distintos paleoclimas, tais como coluvionamentos, mudanças das coberturas florísticas e faunísticas, ações neotectônicas, além das atuais impactantes ações antrópicas, capazes de modificar paisagens em tempos muito curtos.

Em certos casos, nem mesmo a natureza do substrato é simples de ser decifrada, conforme apontado por WHOLERS (1964), reportando-se ao geólogo Sérgio Mezzalira, que mencionava exemplos dessa dificuldade em Piraçununga e Conchal (SP), ora mapeados como Botucatu e ora como Tubarão, "podendo, na realidade, constituírem depósitos mais modernos" (cenozóicos).

Essa complexidade é também exposta por COOPER et al. (2005), ao atribuírem o material de origem de Nitossolos de Piracicaba a uma mistura de diabásios e sedimentos argilosos vermelhos do Quaternário, De fato, nessa província geomorfológica as rochas sedimentares estão muito associadas a intrusivas básicas, podendo ocorrer misturas de produtos de alteração, o que leva a cogitações sobre pedogêneses múltiplas ou superpostas, solos policíclicos ou poligenéticos, comuns nos meios tropicais (THORNBURY 1957, DUCHAUFOUR 1968).

No domínio paulista das "cuestas basálticas", MONIZ \& OLIVEIRA (1974) chegaram a admitir um coluvionamento misturando os materiais de origem do Latossolo Vermelho (Latossolo Roxo) e do Nitossolo (Terra Roxa Estruturada). BJORNBERG \& TOLENTINO (1959) notaram que no Planalto Ocidental, no reverso da cuesta, o contato entre arenito Bauru e lava básica costuma ser pouco nítido, pelo fato de o intemperismo poder alcançar a relativa pequena espessura dos arenitos alterados e assim apagar o contato entre os dois.

A suscetibilidade das rochas básicas na produção de materiais edafizados em curto tempo é ressaltada quando diques de diabásios denudados ocorrem circundados por rochas mais resistentes, como os granitos e gnaisses. Na Rodovia BR 415 (Ilhéus - Barreiras, BA), no município de Itapetinga, solos argilosos sesquioxídicos vermelhos ocupam uma vertente em meio a rochas ácidas praticamente inalteradas, que revelam sinais de dobramento e veios de quartzo, prenunciando a formação de uma stone line que avança em direção ao solo basáltico. 
Mesmo com o progresso promovido pela visão dos solos como sistemas em transformação nas vertentes (CHAUVEL 1972, BOCQUIER 1973), ainda faltam elementos esclarecedores sobre os mecanismos pretéritos que teriam levado os perfis mais desenvolvidos, a montante, a possuírem as atuais características. As transformações a jusante são previsíveis e evidenciadas pela sucessão de horizontes de um perfil para outro nas representações bi e tri-dimensionais propiciadas pela análise estrutural da cobertura pedológica (BOULET et al. 1982, 1990).

Acredita-se que, se às análises de rotina usualmente empregadas forem conjugados dados sedimentológicos, mineralogia e microscopia das frações grossas (areias), seja possível aprofundar o reconhecimento das possíveis relações entre os constituintes dos horizontes e do substrato, ou materiais de áreas vizinhas que possam ter servido como fonte de componentes que entraram nos perfis. É necessário esclarecer que materiais estariam envolvidos na evolução dos perfis, posto que certos minerais presentes não possuem filiação compatível com o substrato presente. Assim é que a composição dos minerais pesados empreendida por MODENESI et al. (1975) em latossolo e em seu substrato de alaskito, na região paulista de Itu, revelou independência genética entre ambos.

De qualquer forma, a identificação dos diferentes tipos de perfis e horizontes pedológicos é fundamental quando se pretende associar pedogênese e morfogênese em pesquisas de detalhe, pela possibilidade de serem encontradas feições ligadas a processos que deixaram de operar e que teriam sido importantes para a modificação da forma das vertentes. Descrições morfológicas apuradas devem preceder essas investigações, levando em conta as minuciosas variações das condições topográficas.

\section{GÊNESE DOS HORIZONTES MICROGRANULARES E POLIÉDRICOS}

Com a evolução dos levantamentos pedológicos no País, o $B$ latossólico acabou sendo identificado com o $\mathrm{Bw}$ norteamericano, de estrutura maciça ou granular muito pequena (microgranular), semelhante a pó-de-café, em solos de rochas básicas (BRASIL 1960).

A estrutura deixou de ser critério diagnóstico (EMBRAPA 2006), aceitando-se Bw em blocos sem revestimentos com cerosidade, como o horizonte coeso de certos Latossolos (RIBEIRO 1998). Passou-se a exigir uma diferença textural pequena em relação ao horizonte imediatamente superior, com uma transição gradual ou difusa, porém, ainda com o limite mínimo de $15 \%$ de argila. Essa organização latossólica pode ser encontrada já nos primeiros estádios de evolução do perfil, ou nos horizontes B incipientes - Bi ou câmbicos.

Horizontes Bt fragmentares, em blocos, prismas ou colunas - poliédricos, como nos Argissolos, Luvissolos e Planossolos, devem apresentar acréscimo significativo no teor de argila abaixo do A gradiente textural elevado, com transições claras ou abruptas entre ambos, diferenciando-se do Bni dos Nitossolos, cujo gradiente textural é muito baixo, mas com expressiva quantidade de cerosidade.

$\mathrm{O}$ Bw e o Bt são representativos das categorias de solos mais desenvolvidos e disseminados dos trópicos úmidos, onde ocupam cerca de $65 \%$ da área total (SÁNCHEZ 1985) e comumente ocorrem associados na paisagem. No Brasil, mais de $60 \%$ do território é recoberto por Latossolos (OLIVEIRA et al. 1992), tanto quanto o Estado de São Paulo, onde os solos com B poliédrico ocupam 30\% (BRASIL 1960).

Os Latossolos ocorrem predominantemente em relevos suaves, maduros ou senis, com drenagem interna boa quando argilosos, ou excessiva, quando de textura média ( 15 a 35\% de argila). Com frequência ocupam antigas superfícies, assim como os Neossolos Quartzarênicos, os quais revelam drenagem interna excessiva e estrutura fraca ou maciça, com teores de argila inferiores a $15 \%$ (geralmente de 8 a 15\%).

Áreas de solos com estruturas poliédricas, em geral sob relevos mais movimentados, em vertentes e com maior quantidade de canais naturais de drenagem, confrontadas com as de Latossolos e Neossolos Quartzarênicos, fornecem indicações sobre o grau de evolução do relevo e, por extensão, sobre a dinâmica da paisagem (ESPINDOLA \& GARCIA 1978, 1979).

Nos primeiros levantamentos pedológicos (BRASIL 1958, 1960) advogava-se a concepção de uma evolução progressiva dos solos e relevo no sentido rocha $\rightarrow$ litossolo $\rightarrow$ solo com $\mathrm{Bt} \rightarrow$ solo com B latossólico, chegando a um estádio final máximo ou clímax. A transformação do Bt em B latossólico dar-se-ia por uma ação homogeneizadora promovida pela fauna edáfica.

Esse sentido evolutivo já era subentendido por NIKIFOROFF (1949), que ponderava que o solo e seu material de origem alcançam um steady state, permanecendo nesta condição enquanto o meio se mostrar estável; porém, tinha dúvida sobre quanto tempo tal estado seria mantido: se apenas por um curto período, ou algo da ordem de milênios.

Para DANIELS et al. (1970), seria mais importante a duração em que determinado processo foi 
ativo e a sua intensidade num tempo considerado, do que o tempo total para a formação do solo $\mathrm{Mu}$ danças internas, controladas principalmente pelas flutuações do lençol freático, representariam o fator primordial na mudança de desenvolvimento do solo ao longo do tempo. Dependendo dos processos em ação, os efeitos do material de origem poderiam ser de curta vida (BARNIHISED \& RICH 1967).

A gênese de perfis diferenciados (microgranulares ou poliédricos) originados de rochas básicas chegou a ser atribuída às naturezas afanítica $\mathrm{e}$ vesicular dos respectivos substratos (GUTMANS 1943 e PAIVA NETTO et al. 1951). Por sua vez, SCHAETZL \& ANDERSON (2005) admitiram diferentes materiais de origem para um mesmo perfil: um horizonte $\mathrm{B}$ avermelhado, fraco e não iluvial poderia advir de um acentuado intemperismo, com acúmulo de óxidos e perda da estrutura da rocha, ou seja, uma transformação direta rocha $\rightarrow$ $\mathrm{Bw}$, sem passar por Bw.

A maioria das explicações para a geração alternativa de um ou outro tipo de horizonte tem sido buscada em hipóteses relacionadas às tensões dos fluxos hídricos, alternâncias secagem-umedecimento, condições de drenagem, flutuações do lençol e aspectos correlatos, reconhecidamente dependentes das condições topográficas, como devidamente contemplado no conceito de catena.

Quando o complexo de alteração possui pouca quantidade de óxidos férricos não é possível manter a floculação das argilas, favorecendo o desenvolvimento de perfis Bt (DE VILLIERS 1962). Nesses casos, movimentos laterais da água no solo, portando compostos solúveis e colóides, exercem importante papel na gênese (DE VILLIERS 1965). Compressões pelo fluxo hídrico foram consideradas responsáveis pela origem dos $\mathrm{Bt}$, enquanto sob drenagem muito eficiente, sem essas pressões, horizontes Bw é que seriam gerados (MONIZ \& BUOL 1982).

Em alterações com elevada produção de sesquióxidos, de pequena mobilidade, agentes mobilizadores, como o clima e a vegetação, podem não se manifestar, favorecendo o desenvolvimento do Bw (VAN WAMBEKE 1967). Para TOWSEND \& REED (1971), a desidratação do ferro e de géis de alumínio pode adquirir um caráter irreversível, pela intensa floculação dos colóides. Cargas da caulinita podem chegar a ser bloqueadas por cátions férricos (CHAUVEL 1972).

QUEIROZ NETO (1970) admitiu que, nos estádios iniciais de intemperismo, o desaparecimento de minerais primários alteráveis acarretaria um decréscimo da capacidade de troca iônica e da relação silte/argila. Uma migração de componentes finos iria constituir um horizonte Bt, que aos poucos se espessaria, diferenciando-se do horizonte superficial. Posteriormente, sua degradação apagaria a distinção entre as partes superior e inferior, resultando um perfil latossólico.

Outra feição que QUEIROZ NETO (1976) atribuiu a essa transformação foi a ocorrência de perfis com características intermediárias (intergrades), com $\mathrm{Bt}$ sobreposto a $\mathrm{Bw}$, resultado da progressiva diminuição no arraste de finos do $\mathrm{Bt}$ e de maior perda de bases. Esse mecanismo poderia até culminar com a remoção erosiva do horizonte superficial à medida que o perfil fosse assumindo caráter predominantemente latossólico, ampliando a homogeneização do solo resultante.

Para esses perfis intergrades, ou bimodais, comuns em Argissolos, Luvissolos e Nitossolos, COLTRINARI et al. (1978) encontraram um caminho genético explicativo inverso: o B textural é que se organizaria no topo de um horizonte de perfil latossólico, com migração de argilas até uma certa profundidade, em consequência de desequilíbrios no regime hídrico operante, sobretudo por remoção da cobertura vegetal.

Considerava-se, inicialmente, que apenas superfícies de erosão terciárias comportariam esses solos microagregados, posto que oriundos de materiais remanejados - uma formação superficial com mecanismos de instalação ainda mal conhecidos ou mal definidos. Posteriormente, os solos com Bt foram também assim entendidos, com a pressuposição de que as condições locais para migração ou imobilização das argilas é que iriam conduzir o desenvolvimento para uma direção ou outra (QUEIROZ NETO et al. 1981).

LEPSCH et al. (1977) também defenderam a formação de Bt a partir de materiais alterados de latossolos remanescentes em superfícies antigas, por influência de movimentos laterais de água e redução dos óxidos de ferro, processo esse que poderia se desenvolver num curto espaço de tempo. A transformação $\mathrm{Bw} \rightarrow \mathrm{Bt}$ nas vertentes foi amplamente explorada na análise estrutural da cobertura pedológica, contudo PÉDRO et al. (1976) já haviam admitido tanto esse mecanismo como o da evolução progressiva, nas "terras roxas" do Médio Tietê.

A concepção regressiva foi empregada por KAWAKUBO et al. (2006) para os Neossolos Quartzarênicos de São Pedro, SP, cuja elevada porosidade e permeabilidade facilitam a translocação de argilas e a consequente formação de Argissolos ao longo das encostas. Essa associação de ambos na paisagem estende-se a Santa Maria, São Manuel e Botucatu, com a ocorrência de pequenas bacias 
hidromórficas fechadas em posições de topo (ESPINDOLA \& CARVALHO 1986).

É possível admitir que transformações desse tipo estejam se intensificando nos tempos atuais, com os desmatamentos acelerando mecanismos naturais e provocando desequilíbrios hídricos nas coberturas pedológicas. De acordo com CHAUVEL (1983), o deflorestamento pode provocar uma destruição da estrutura microgranular em apenas algumas dúzias de anos; porém, a reorganização dos constituintes em nova organização estrutural demandaria um tempo da ordem de milênios.

Modificações em padrões vegetativos como o das florestas tropicais úmidas requerem apenas um ou dois séculos para atingir o seu climax, mas para profundas alterações ferralíticas dos solos esse tempo requer dezenas de milhares de anos e ainda muito mais tempo para o desenvolvimento de um modelado tropical característico, após as alterações já terem atingido uma espessura suficiente (TRICART 1968).

Nos solos basálticos do Médio Tietê apenas o Latossolo Roxo de Jaú ( $\left.\operatorname{LR}_{1}\right)$, de uma superfície mais antiga, possui organização integralmente latossólica. $\mathrm{Na}$ área vizinha, em Barra Bonita, o LR apresenta sinais de cerosidade, e a Terra Roxa Estruturada (TE) tem perfil bimodal - Bni sobre Bw (ESPINDOLA \& ALONSO 1983).

$\mathrm{Na}$ superfície mais antiga os minerais transparentes pesados e leves são equilibrados $(50 \%$ em peso), com diminuição dos primeiros nas posições rejuvenecidas do relevo, além da distribuição muito caótica tanto entre perfis, como nos distintos horizontes do mesmo perfil; muitos dos pesados são atípicos dos basaltos, ou seja, são alogênicos (ESPINDOLA 1979).

Descarta-se a possibilidade de os solos da superfície mais recente terem sido gerados das camadas mais profundas do $\mathrm{LR}_{1}$, como ocorre em Echaporã, São Paulo (LEPSCH et al. 1977). A própria composição granulométrica dos perfis contraria essa possibilidade. Os intergrades sugerem uma evolução Bt posterior à constituição do $\mathrm{Bw}$, como indica a fraca e pouca cerosidade no $\mathrm{LR}_{2}$. Mesmo os solos litólicos apresentam revestimentos argilosos, de elevada birrefringência ao microscópio, que chegam a recobrir também os basaltos em alteração (ESPINDOLA 1979).

Admite-se que a inclusão de alógenos se verifique em diferentes momentos da evolução dos solos e do relevo, em conformidade com as condições ambientais vigentes: vigor do transporte, quantidades transportadas e situações topográficas (ESPINDOLA 2009).

Esses dados consubstanciam que as transformações de um solo em outro não são completas, subsistindo horizontes e características relictuais dos estádios precedentes, principalmente na base dos perfis, posto que, por autoevolução, as acumulações e transformações as tornam cada vez mais superficiais (BOCQUIER 1973). Todavia, mesmo certos minerais pesados são passíveis de alteração (SOYER 1972).

A ampla distribuição dos latossolos nos trópicos pode sugerir que tanto a evolução progressiva tenha intensamente operado ao longo do tempo (Bt $\rightarrow \mathrm{Bw}$ ), como a transformação rocha $\rightarrow$ organização latossólica seja o principal mecanismo. Esta última consubstancia a preocupação de RUELLAN \& DOSSO (1993), evitando representar por B o horizonte latossólico. Com efeito, é comum identificar uma organização estrutural dessa natureza também em horizontes $\mathrm{C}$ ou em horizontes câmbicos - Bi sem passar por um estágio Bt.

A via condizente com uma evolução regressiva foi pioneiramente entrevista na Amazônia brasileira (KLINGE 1965), com a transformação de um latossolo em podzol, pesquisa retomada e enriquecida por TURENNE (1977) na Guiana Francesa. A quase totalidade das investigações em topossequências do Brasil, com o emprego da micromorfologia, explorou a transformação do Bw em Bt (CASTRO 1989).

Todavia, não foram contestadas investigações efetuadas por PÉDRO et al. $(1973,1976)$ que evidenciaram os dois sentidos de transformação. A via mais ignorada, $\mathrm{Bt} \rightarrow \mathrm{Bw}$ (progressiva) ocorreria pela deionização contínua dos constituintes, acompanhada por uma ferrização (sic) superficial dos componentes secundários e inativação progressiva do material argiloso; estaria aí envolvida uma alteração ferralítica seguida de uma evolução ferralítica. Para PERECIN \& CAMPOS (1976), também ambas as vias de transformação devem ser encaradas como processos dinâmicos.

BEAUDOU (1972) constatou que arranjos plásmicos do Bt podem evoluir para uma microagregação destituída de cutãs de iluviação; NETTLETON et al. (1969) já haviam verificado que secagem e umedecimento alternados podem destruir cutãs no próprio horizonte, mantida a sua organização em blocos, o que pode representar transição para uma transformação mais intensa que conduza a estrutura poliédrica a uma conformação latossólica.

A evolução regressiva parece tornar mais fácil e lógica a compreensão do binômio pedogênese-morfogênese, pois a autoevolução do solo cria mecanismos internos de subtração de constituintes (erosão geoquímica), modificando as organizações estruturais no seio dos perfis e, por consequência, o modelado superficial. Em zonas cársticas esse processo gera dolinas, mas em outros substratos con- 
corre para criar novos modelados superficiais, por subtração de volumes internos dos mantos alterados.

Reflexos dessa autoevolução são denunciados por abatimentos na superfície, em geral na forma de depressões hidromórficas fechadas, inicialmente desvinculadas da rede de drenagem natural, conferindo um padrão aerofotogramétrico de baixo grau de integração dos compartimentos topográficos envolvidos (LUEDER 1959). Na mencionada região basáltica do Médio Tietê, o antigo $\mathrm{LR}_{1}$ é entremeado por essas bacias hidromórficas fechadas de topo (ESPINDOLA et al.1981).

As depressões inicialmente isoladas dão início a uma modificação do relevo por posterior incorporação delas à rede de drenagem, que se ramifica com o entalhe da superfície, criando vertentes e expondo rochas nas incisões mais profundas. Esse rejuvenescimento do relevo propicia o truncamento de porções de antigos solos e a instalação de novos mecanismos pedogenéticos, impelidos pelas modificações das condições de circulação hídrica externa e interna, criando solos mais jovens.

Condição análoga já havia sido apontada por CASTRO FRANÇOSO et al. (1974), em substrato de argilitos do platô de Itapetininga (SP), com bacias doliniformes associadas aos latossolos. Também nos Neossolos Quartzarênicos a mesma feição é encontrada (ESPINDOLA \& CARVALHO 1986), demonstrando que o mecanismo autoevolutivo é genérico para qualquer embasamento litológico inserido na dinâmica do relevo.

No Nitossolo Vermelho eutroférrico latossólico (Bni sobre Bw), COOPER et al. (2005) mostraram que uma transformação parcial da estrutura em blocos do Bni deu origem a agregados miúdos de formatos variados. Os ovais associados ao quartzo foram atribuídos à ação mecânica da mesofauna (cupins e formigas); os ovais sem quartzo, a mecanismo químico-biológico, e os agregados poliédricos, a fissurações da matriz por efeitos sazonais de expansão e contração, intensificados pelo desmatamento e introdução de pastagens.

Contudo, não é esclarecido se a estrutura nítica mais próxima à superficie provém da transformação do Bw abaixo, já que as constatações referem-se justamente à transformação do Bni em Bw. Poder-se-ia, talvez, imaginar uma transformação inicial do substrato, gerando um perfil Bw, para depois este transformar-se em Bni, o qual, posteriormente, voltaria a transformar-se, gerando os agregados miúdos.

Na prática, não se encontram perfis em que o horizonte poliédrico ocorre sob o microagregado, sendo mais plausível admitir que as camadas su- perficiais sejam mais sujeitas a mecanismos mobilizadores, capazes de gerar horizontes poliédricos sobre as camadas microagregadas abaixo, mais antigas e menos suscetíveis a pedoturbações e variações sazonais de umidade.

À complexidade dessas transformações, juntem-se feições por vezes tomadas como indicativas da contemporaneidade ou antiguidade dos processos envolvidos, como é o caso das diversas formas lateríticas. Nem sempre elementos tomados como relictuais (couraças, carapaças, nódulos, concreções) são confiáveis ou reais registros dos momentos em que foram gerados.

LEPRUN (1977) e TARDY (1993) contestaram a antiguidade de couraças africanas, pressuposta por inúmeros estudiosos, pela possibilidade de formação e destruição daqueles depósitos sob as condições atuais. Evidências análogas foram encontradas em Guaíra, SP (KERTZMAN 1989, LADEIRA 1995) e em Londrina, PR (FERNANDES BARROS \& QUEIROZ NETO 1994).

Parece ter sido relegada ao esquecimento a tese de Reinhard Maack — desenvolvida em 1948, apresentada e aprovada na II Reunião Brasileira de Ciência do Solo e posteriormente transcrita no Boletim Geográfico (MAACK 1950) - , na qual ele apontava a destruição de lateritos paranaenses pelas atuais condições climáticas, gerando solos do tipo feralitos, segundo nomenclatura de VAGELER (1933).

As modernas técnicas de datação absoluta vêm substituindo as simples conjecturas empregadas em datações relativas, agregando conhecimentos mais consistentes. À tradicional radiometria de carbono, efetuada sobre vestígios de constituintes orgânicos (PESSENDA 1991), podem ser acrescentadas técnicas que possibilitam maior recuo no tempo geológico, como a termoluminescência sobre grânulos minerais (DULLER 2004).

Pela termoluminescência opticamente estimulada - LOE sobre grãos de quartzo, TATUMI et al. (2006) dataram colúvios do noroeste paulista (935 a 103 mil anos AP) e SALLUN \& SUGUIO (2007) esclareceram a natureza de sedimentos responsáveis pela formação de terraços fluviais do Alto Rio Paraná.

Outro recurso analítico ainda pouco difundido no meio pedológico nacional é o emprego de isótopos cosmogênicos, como o ${ }^{10} \mathrm{Be}$ ou o ${ }^{26} \mathrm{Al}$, para estimar a velocidade de produção de regolito pelo intemperismo (SMALL et al. 1999). O aquecimento induzido a laser de grãos minerais em relações isotópicas, como ${ }^{40} \mathrm{Ar} /{ }^{39} \mathrm{Ar},{ }^{87} \mathrm{Sr} /{ }^{86} \mathrm{Sr}$, ou ${ }^{187} \mathrm{Os} /{ }^{186} \mathrm{Os}$, vem tendo aplicação crescente (CARMO \& VASCONCELOS 2004, 2006; VASCONCELOS et al. 2002). 
Mesmo com a introdução de técnicas avançadas persistem dúvidas sobre a gênese das stone lines. As últimas revisões revelam que, embora certos pesquisadores tendam a privilegiar uma das vias - in situ ou retrabalhamento - mediante sofisticada instrumentação (BRAUCHER et al. 2004, BROWN et al. 2004), ambas acabam sendo admitidas, a depender da situação em estudo.

Esse esclarecimento se afigura fundamental para legitimar ou refutar tradicionais representações cartográficas que associaram solos e superfícies usando datações relativas (MABESOONE \& LOBO 1980, PÉDRO \& VOLKOFF 1984). Para situações dessa natureza, investigações de determinados horizontes pedológicos, alteritas e substratos líticos que possam estar supostamente associados devem ser buscadas em datações absolutas.

\section{CONSIDERAÇÕES FINAIS}

Na presente revisão não se cogitou abordar a ação antrópica na evolução das paisagens, de reconhecidos efeitos avassaladores (VITEK \& GIARDINO 1993). Porém, esta questão tem sido amplamente divulgada na atualidade, além de devidamente incorporada aos diferentes níveis de ensino, como demonstra a programação do V Simpósio Brasileiro de Educação em Solos realizado em Curitiba, em abril de 2010. Nem mesmo faltaram relatos específicos sobre as relações solo-paisagem (RITTL \& COOPER 2010) ou solo-relevo (JANJAR 2010).

$\mathrm{O}$ caráter correlativo do solo em relação à superfície em que repousa deve merecer, em termos de idade relativa, especial atenção. Em geral, uma superfície nunca é suficientemente homogênea para conter apenas uma classe de solo. Além disso, a superfície gerada comportaria apenas materiais edafizados, ou também rochas e fragmentos rudáceos? O espessamento evolutivo do solo seria acompanhado por mecanismos capazes de levar detritos grosseiros a constituir uma stone line?

À subjetividade que usualmente permeou o discurso sobre a evolução das paisagens vêm sendo crescentemente adicionados dados mensuráveis e procedimentos mais detalhados de campo, tais como o emprego de infiltrômetros (PORTILHO \& ALMEIDA 2008) e do radar de penetração no solo - GPR (UCHA et al. 2010), antes adstritos a outros ramos do conhecimento científico. O emprego da sedimentologia e de datações absolutas faz vislumbrar avanços ainda mais consistentes.

Esclarecimentos dessa natureza poderão aproximar o pedólogo da condição que ele mais almeja, na visão de RUELLAN (1986), qual seja, desvendar a história do solo - a sua $4^{a}$ dimensão. Isso ainda requer, pelo menos, a inserção de análises sedimentológicas e mineralógicas das frações grossas (as areias), as quais podem portar componentes residuais de um passado que o intemperismo não conseguiu apagar. $\mathrm{O}$ mesmo se diga para uma interpretação mais definitiva das stone lines e suas possíveis filiações.

Em pedogênese há que lastimar o abandono da fração areia dos solos, que teve mais expressão há cerca de quatro décadas (MARCONI 1969, ALTAFIN 1977). Na pedologia vigente nas ciências agrárias a gênese ficou praticamente restrita às sequências de intemperismo das argilas, enquanto a evolução dos solos-relevo tem sido mais explorada na geografia, com a micromorfologia intermediando ambos os domínios, além de importante suporte à geologia de engenharia. A interação de pesquisadores de diversas áreas, defendida por TRICART (1968), deve ser intensificada nos tempos atuais, com os recursos metodológicos que surgiram nos últimos tempos.

Determinadas conjecturas antigas, porém muito judiciosas, parecem ter sido esquecidas, senão ignoradas pela comunidade científica, e, por vezes, ressurgem travestidas de novas proposições ou roupagens. Outras já se transformaram em verdadeiros dogmas ou paradigmas, sem as devidas contestações que enriqueceriam o debate epistemológico necessário a uma ciência que evolui (GOMES \& ESPINDOLA 2007).

Felizmente, alguns pesquisadores resgatam matérias julgadas ultrapassadas, acrescentando novas visões interpretativas e críticas, graças aos seus conhecimentos acumulados, servindo como exemplo a estigmatizada ciclicidade do relevo, habilmente retomada por MABESOONE (2000). Louve-se a disposição de outros em reverem posturas anteriormente assumidas, como as demonstradas por QUEIROZ NETO $(2000,2008)$, a respeito de stone lines e lateritas.

Uma geopedologia é advogada por GOULART \& GIMENES (2008) na identificação de processos geradores das formas, em vez da simples adoção de modelos pré-estabelecidos. Por analogia, valeria a pena acrescentar o incremento de termos como morfopedogênese, pedomorfogênese ou geopedogênese, em prol de uma morfogênese-pedogênese substituindo a dualidade. Poder-se-ia pensar, então, na seguinte representação da gênese das formações superficiais, numa adaptação à consagrada formulação matemática de JENNY (1941):

Solo/Relevo $=f$ (material de origem, clima, organismos, tempo) 


\section{REFERÊNCIAS BIBLIOGRÁFICAS}

AB'SÁBER, A.N. 1957. Conhecimento sobre as flutuações climáticas do Quaternário no Brasil. Boletim da Sociedade Brasileira de Geologia, 6: 41-48.

AB'SÁBER, A.N. 1962. Revisão dos conhecimentos sobre o horizonte superficial de cascalhos inhumados do Brasil Oriental. Boletim da Universidade do Paraná, Geografia Física, 2: 1-32.

AB'SÁBER, A.N. 1972. Participação das depressões periféricas e superfícies aplainadas na compartimentação do Planalto Brasileiro. São Paulo: Instituto de Geografia - USP, 38 p. (Geomorfologia, 28).

AGAFONOFF, V. 1932. Sur quelques sols latéritiques rouges et jaunes du Brésil. Soil Research, 3: 13-20.

ALTAFIN, A. 1977. Granulometria da fração grosseira de solos desenvolvidos sobre Arenito Bauru. Escola Superior de Agricultura Luiz de Queiroz, Universidade de São Paulo, Piracicaba, Dissertação de Mestrado, 90 p.

AUBERT, G.; CAILlEUX, A. 1962. Esboço de um estudo sobre solos. Boletim Geográfico, 168: 245-257.

AZEVEDO, A.C.; DALMOLIN, R.S.D. 2004. Solos e Ambiente - uma introdução. Palotti, Santa Maria, $100 \mathrm{p}$.

BALDWIN, M.; KELLOGG, C. E.; THORP, J. 1938. Soil classification. In: U. S. Dept. of Agriculture (ed.) Yearbook of Agriculture 1938 - Soils and Men, p. 979-1001.

BARBOSA, O. 1959. Quadro provisório das superfícies de erosão e aplainamento no Brasil. Notícia Geomorfológica, 4: 31-33.

BARNHISED, R.I.; RICH, C.I. 1967. Clay mineral formation in different rock types of weathering boulder conglomerate. Soil Scence Society of America Proceedings, 31: 627-631.

BARTORELLI, A.; HARALYI, N. 1998. Geologia do Brasil. In: A.M.S. Oliveira \& S.N.A. Brito (Eds.) Geologia de Engenharia. São Paulo, ABGE, Cap. 4, p. 2-24.

BEAUDOU, A.G. 1972. Expression micromorphologique de la microagrégation et de l'illuviation dans les horizons de sols ferralitiques centraficains et des sols hydromorphes associés. Cah. Orstom, Sér. Pédol., 10: 357-371.

BELCHER, D.J. 1945. The engineering significance of soil patterns. Photogrammetric Engineering, 11: $115-148$.

BENNEMA, J.; CAMARGO, M.N.; WRIGHT, A.C.S. 1962. Regional contrasts in South American soil formation in relation to soil classification and soil fertility. In: INTERNATIONAL SOIL CONFERENCE, New Zealand, Transactions, 2-15.

BIGARELLA, J.J.; MOUSINHO, M.R.; SILVA, J.X. 1965. Pediplanos, pedimentos e seus depósitos no Brasil. Boletim Paranaense de Geografia, 16/17: 117-152.

BIROT, P. 1968. Précis de Géographie Physique Générale. Librairie Armand Colin, 3 ed., Paris, $340 \mathrm{p}$.

BJORNBERG, A.J.S.; TOLENTINO, M. 1959. Contribuição ao estudo da geologia e águas subterrâneas em São Carlos. Boletim da Sociedade Brasileira de Geologia, 8: 5-34.

BOCQUIER, G. 1973. Genèse et évolution de deux toposéquences de sols tropicaux du Tchad. Paris: ORSTOM, 350 p. (Mémoires, 62).

BOCQUIER, G.; MULLER, J.P.; BOULANGÉ, B. 1984. Les latérites. Connaissances et perspectives actuelles sur les mecanismes de leur differentiation. In: AFES, Livre Jubilaire du Cinquantenaire, Paris, 123-138.

BOULET, R.; CHAUVEL, A.; HUMBELL, F.X.; LUCCAS, Y. 1982. Analyse structurale et cartographie en pédologie. I. Prise en compte de l'organisation bidimensionelle de la couverture pédologique. Cahiers Orstom, Série Pédologie, 19: 309-321.

BOULET, R.; CHAUVEL, A.; LUCCAS, Y. 1990. Os sistemas de transformação em pedologia. Boletim de Geografia Teorética, 20: 45-63.

BRASIL. 1958. Levantamento de Reconhecimento dos Solos do Estado do Rio de Janeiro e Distrito Federal. Rio de Janeiro: Comissão de Solos do Serviço Nacional de Pesquisas Agronômicas (Boletim, 11).

BRASIL. 1960. Levantamento de Reconhecimento dos Solos do Estado de São Paulo. Rio de Janei- 
ro: Comissão de Solos do Serviço Nacional de Pesquisas Agronômicas, 634 p. (Boletim, 12).

BRASIL. 1962. Levantamento de Reconhecimento dos Solos da Região sob Influência do Reservatório de Furnas. Rio de Janeiro: Comissão de Solos do Serviço Nacional de Pesquisas Agronômicas, 462 p. (Boletim, 13).

BRAUCHER, R.; BOURLÈS, D.L.; COLIN, F.; BROWN, E.T.; BOULANGÉ, B. 1998. Brazilian laterite dynamics using in situproduced ${ }^{10} \mathrm{Be}$. Earth and Planetary Science Letters, 163: 197-205.

BRAUCHER, R.; LIMA, C.V.; BOURLÈS, D.L.; GASPAR, J.C.; ASSAD, M.L.L. 2004. Stone-line formation processes documented by in situ-produced ${ }^{10} \mathrm{Be}$ distribution, Jardim River basin, DF, Brazil. Earth and Planetary Science Letters, 222: 645-651.

BROWN, D.J.; Mc SWEENEY, K.; HELMKE, P.A. 2004. Statistical, geochemical, and morphological analysis of stone line formation in Uganda. Geomorphology, 62: 217-237.

CAMARGO, M.N.; KLAMT, E.; KAUFFMAN, J.H. 1987. Classificação de solos usada em levantamentos pedológicos no Brasil. Boletim Informativo, Sociedade Brasileira de Ciência do Solo, 12: 11-33.

CANADA. 1987. The Canadian system of soil classification (CSSC). 2 ed. Agriculture Canada Expert Committee on Soil Survey. Research Branch, Agriculture Canada, 164p. (Publ., 164).

CARMO, I.O.; VASCONCELOS, P.M. 2004. Geochronological evidence for pervasive Miocene weathering, Minas Gerais, Brazil. Earth Surface Processes and Landforms, 29: 1303-1320.

CARMO, I.O.; VASCONCELOS, P.M. 2006. ${ }^{40} \mathrm{Ar} /{ }^{39} \mathrm{Ar}$ geochronology constraints on late miocene weathering rates in Minas Gerais, Brazil. Earth and Planetary Science Letters, 241: 80-94.

CARVALHO, 1970. A study of Terra Roxa Estruturada and Latossolo Roxo on a topographic sequence in São Paulo State, Brazil. University New Castle upon Tyne, New Castle upon Tyne, Thesis Master Science, 93p.
CASTRO, S.S. 1989. Sistemas de transformação pedológica em Marília, SP - B latossólicos e B texturais. Faculdade de Filosofia, Letras e Ciências Humanas, Universidade de São Paulo, São Paulo, Tese de Doutorado, 274 p.

CASTRO FRANÇOSO, S.S.; AILLAUD, C.; QUEIROZ NETO, J.P. 1974. Depressões doliniformes do platô de Itapetininga - tentativa de interpretação. In: CONGRESSO BRASILEIRO DE GEOLOGIA, 28, Porto Alegre, Anais, 3: 85-90.

CHAUVEL, A. 1972. Observation micromorphologique de la partie supérieure des sols rouges ferralitiques de Casamance (Sénégal). Essai d'interprétation de la dynamique actuelle, sous couverture forestier. Cahiers Orstom, Série Pédologie, 10: 343-356.

CHAUVEL, A. 1983. La cartographie consideré comme un moyen d'étude de la pédogenèse et de l'histoire des sols: application aux sols de Moyenne Casamance (Sénegal). In: Instituto de Geografia - USP, COLÓQUIO INTERDISCIPLINAR FRANCO-BRASILEIRO "ESTUDO E CARTOGRAFIA DE FORMAÇÕES SUPERFICIAIS E SUAS APLICAÇÕES EM REGIÕES TROPICAIS", São Paulo, 1978, Comunicações e Debates, 1: 279-294.

COCKBURN, H.A.P.; SUMMERFIELD, M.A. 2004. Geomorphological applications of cosmogenic isotope analysis. Progress in Physical Geography, 28: 1-42.

COLTRINARI, L.; COUTARD, J.P.; NAKASHIMA, P. 1978. Itinerário de excursão ao Vale do Parateí, SP. In: FFLCH-USP, COLÓQUIO INTERDISCIPLINAR FRANCO-BRASILEIRO "ESTUDO E CARTOGRAFIA DE FORMAÇÕES SUPERFICIAIS E SUAS APLICAÇÕES EM REGIÕES TROPICAIS", São Paulo, Guias das Excursões, 2: 11-28. É CITADO??

COOPER, M.; VIDAL-TORRADO, P.; CHAPLOT, V. 2005. Origin of microaggregates in soils with ferralitic horizons. Scientia Agricola, 62: $256-263$.

COUTARD, J.P.; DIAS FERREIRA, R.P.; PELLERIN, J. ; QUEIROZ NETO, J.P. 1983. A bacia sedimentar do Paraná. In: Instituto de Geografia - USP, COLÓQUIO INTERDISCIPLINAR FRANCO-BRASILEIRO "ESTUDO E 
CARTOGRAFIA DE FORMAÇÕES SUPERFICIAIS E SUAS APLICAÇÕES EM REGIÕES TROPICAIS", São Paulo, 1978, Comunicações e Debates, 3: 31-43.

DANIELS, R.B.; GAMBLE, E.E.; CADY, J.G. 1970. Some relations among Coastal Plain soils and geomorphic surfaces in North Carolina. Soil Science Society of America Proceedings, 34: 648-653.

DELVIGNE, J. Pédogenèse en zone tropicale. La formation des minéraux secondaires en milieu ferralitique. Dunod/Orstom, Paris, 177 p.

DE MARTONNE, E. 1943. Problemas morfológicos do Brasil Tropical Atlântico. Revista Brasileira de Geografia, 4: 523-550.

DE PLOEY, J. 1985. O estudo de processos geomorfológicos e a interpretação dos depósitos quaternários. Revista do Instituto Geológico, 6: 7-13.

DE VILLIERS, J.M. 1962. A study of soil formation in Natal. Pietermaritzburg, Department of Soil Science, University of Natal, PhD Thesis, $256 \mathrm{p}$.

DE VILLIERS, J.M. 1965. Present soil-forming factors and processes in tropical and subtropical regions. Soil Science, 99: 50-57.

DIAS FERREIRA, R. P.; QUEIROZ NETO, J.P. 1974. Sequências de alteração na região da Serra do Limoeiro, SP. In: SBG, CONGRESSO BRASILEIRO DE GEOLOGIA, 28, Porto Alegre, Anais, 50-58.

DOKUCHAEV, V.V. 1893. The Russian steppes and study of the soil in Russia, its past, and present. St Petersburg, Dept Agric. Min. Crown Domains.

DUCHAUFOUR, P. 1968. L'Évolution des sols. Essai sur la dynamique des profis. Masson, Paris, 94p.

DUCHAUFOUR， P.; LELONG， F. 1967. Entrainement ou destruction d'argile dans les horizons éluviaux des sols lessivés. C.R. Acad. Paris, t. 264, Sér. D: 2884-2887.

DULLER, G.A.T. 2004. Luminescence dating of Quaternary sediments: recent advances. Chichester, Journal of Quaternary Science, 19: 183-192.
DUNBAR, R.A. 1950. Problems of interpretation in tropical regions. In: Aerial Photographic Interpretations: Principles and Applications. New York, McGraw Hill, p. 426-427.

EMBRAPA. EMPRESA BRASILEIRA DE PESQUISA AGROPECUÁRIA. 2006. Sistema Brasileiro de Classificação de Solos. Embrapa Solos, Rio de Janeiro, $2^{\text {a }}$ ed.

ERHART, H. 1956. - La génèse des sols en tant que phénomène géologique. Masson, Paris, $90 \mathrm{p}$.

ESCHENBRENNER, V. 1986. Contribution des termites à la micro-agrégation des sols tropicaux. Cahiers Orstom, Série Pédologie, 22: 397-408.

ESPINDOLA, C.R. 1977. Relações entre os solos e elementos da paisagem na zona do Baixo Rio do Peixe (Região Conchas-Anhembi, SP). Escola Superior de Agricultura Luiz de Queiroz, Universidade de São Paulo, Piracicaba, Dissertação de Mestrado, 113 p.

ESPINDOLA, C.R. 1979. Pedogênese em áreas basálticas de reverso de cuestas no médio curso do Rio Tietê. Faculdade de Ciências Agronômicas, Universidade Estadual Paulista, Botucatu, Tese de Livre Docência. 212 p.

ESPINDOLA, C.R. 2008. Retrospectiva Crítica sobre a Pedologia - um repasse bibliográfico. Editora da Unicamp, Campinas, 397 p.

ESPINDOLA, C.R. 2009. Minerais alógenos em materiais de origem dos solos. In: CONGRESSO BRASILEIRO DE CIÊNCIA DO SOLO, 32, Fortaleza, Resumos, 229 e Resumo Expandido em CD-ROM, 2 p.

ESPINDOLA, C.R. 2010. Descompassos entre a geomorfologia e a pedologia no estudo da evolução da paisagem. In: UGB, SIMPÓSIO NACIONAL DE GEOMORFOLOGIA, 7, Recife, Palestra - Mesa Redonda "Relação Morfogênese x Pedogênese".

ESPINDOLA, C.R.; ALONSO, O. 1983. Características gerais e classificação de solos basálticos da região central do Estado de São Paulo. Boletim de Geografia Teorética, 13: 55-65.

ESPINDOLA, C.R.; CARVALHO, W.A. 1986. Relações entre a natureza dos solos e suas posições na paisagem na Bacia do Capivara (Botucatu-SP). Cientifica, 14: 29-37. 
ESPINDOLA, C.R.; GARCIA, G.J. 1978. Interpretação fotográfica de redes de drenagem em diferentes categorias de solos. Notícia Geomorfológica, 18: 71-94.

ESPINDOLA, C.R.; GARCIA, G.J. 1979. Relação entre graus de desenvolvimento de mantos de alteração e evolução de suas redes de drenagem. Notícia Geomorfológica, 19: 29-40.

ESPINDOLA, C.R.; GARCIA, G.J.; GALHEGO, H.R. 1980. Pedogênese na região Conchas-Anhembi, SP. Notícia Geomorfológica, 20: $35-48$.

ESPINDOLA, C.R.; GALHEGO, H.R.; GARCIA, G.J. 1981a. Desenvolvimento de bacias hidromórficas fechadas em superfícies de latossolos argilosos. Notícia Geomorfológica, 21: 119-131.

ESPINDOLA, C.R.; GALHEGO, H.R.; GONÇALVES, N.M.M. 1981b. Natureza do quartzo em produtos de alteração de basaltos em Barra Bonita-Jaú, SP. In: JORNADA CIENTÍFICA DE BOTUCATU, 10, Botucatu, Anais, p. 70.

ESPINDOLA, C.R.; QUEIROZ NETO, J.P. ; GALHEGO, H.R. 1983. Relações entre os solos e o relevo na zona do Baixo Rio do Peixe (Região Conchas-Anhembi, SP). In: Instituto de Geografia - USP, COLÓQUIO INTERDISCIPLINAR FRANCO-BRASILEIRO "ESTUDO E CARTOGRAFIA DE FORMAÇÕES SUPERFICIAIS E SUAS APLICAÇÕES EM REGIÕES TROPICAIS”, São Paulo, 1978, Comunicações e Debates, 1: 311-322.

FAUCK, R.; LAMOUROUX, M.; PERRAUD, A.; ROEDERER, P.; VIELLEFON, J.; SÉGALEN, P. 1979. Projet de Classification des Sols. ORSTOM, Paris, Services Scientifiques Centraux (Mimeo), $301 \mathrm{p}$.

FELLER, C.; BROWN, G.G.; BLANCHAT, E.; DELEPORTE, P.; CHERNYANSKII, S.S. 2003. Charles Darwin, earthworms and the natural sciences: various lessons from past to future. Agriculture, Ecosystems and Environment, 99: 29-49.

FELLER, C.; BLANCHART, E.; YAALON, D.H. 2006. Some major scientists (Palissy, Buffon, Thäer, Darwin and Müller) have described soil profiles and developed soil survey techniques before 1883. In: B.P. Warkentin (ed.) Footprints in the soil: people and ideas in soil history. Elsevier, 572 p.

FERNANDES BARROS, O.N.; QUEIROZ NETO, J.P. 1994. Microagrégation des sols, cuirasses ferrugineuses et altération des basaltes à Londrina (État du Paraná, Brésil). In: INTERNATIONAL CONGRESS OF SOIL SCIENCE, 15, Acapulco, Transactions, 62-63.

FRANÇA, G.V. 1968. Interpretação fotográfica de bacias e redes de drenagem aplicada a solos da região de Piracicaba. Escola Superior de Agricultura Luiz de Queiroz, Universidade de São Paulo, Piracicaba, Tese de Doutorado, 151 p.

FREITAS, R.O. 1951. Ensaio sobre a tectônica moderna no Brasil. São Paulo: FFCL/USP, Geologia 6, 120p.(Boletim, 130).

GOMES, R.D.; ESPINDOLA, C.R. 2007. Interdisciplinaridade sistêmica e estudos geográficos. Desenvolvimento e Meio Ambiente, 16: 95-114.

GOULART, A.C.O.; GIMENES, A.C.W. 2008. Geopedologia em um ensaio metodológico de investigação das relações estruturais do relevo. In: UGB, SIMPÓSIO NACIONAL DE GEOMORFOLOGIA, 7 e ENCONTRO LATINOAMERICANO DE GEOMORFOLOGIA, 2, Belo Horizonte, Anais, CD-Rom.

GUPTA, A. 1993. The changing geomorphology of the humid tropics. In: J.D. Vitek \& J.R. Giardino (eds.) Geomorphology: The research frontier and beyond. BINGHAMTON SYMPOSIUM IN GEOMORPHOLOGY, 24, Amsterdam, Elsevier, Proceedings, p. 165-186.

GUTMANS, M. 1943. Rochas-mater da "Terra Roxa”. Bragantia, 3: 271-321.

HIRUMA, S.T. 2007. Revisão dos conhecimentos sobre o significado das linhas de seixos. Revista do Instituto Geológico, 27/28 (1/2): 53-64.

JANJAR, C. 2010. Estudo da relação solo-relevo com alunos do ensino médio: atividades práticas. In: M.R. Lima (ed.) SIMPÓSIO BRASILEIRO DE EDUCAÇÃO EM SOLOS, 5, Curitiba, Resumos Expandidos, p. 236-238.

JENNY, H. Factors of Soil Formation. 1941. McGraw-Hill, New York, 281 p. 
JUNGERIUS, P.D.; VAN DER ANCKER, J.A.M.; MUCHER, H.J. 1999. The contribution of termites to microgranular structure of soils on the Uasin Gishu Plateau, Kenya. Catena, 34: 349-363.

KALPAGÉ, F.S.C.P. 1976. Tropical soils. Classification, fertility and management. MacMillan Press, London, 283p.

KAWAKUBO, F.S.; OLIVEIRA, D.; MORATO, R.G. 2006. Contribuição da análise de superfície de tendência para caracterização morfológica de uma topossequência situada na região de São Pedro-SP. Geografia, 31: 571-585.

KAY, G.F. 1931. Origin of the pebble-band on Iowan till. Jour. Geol., 39: 377-380.

KELLOGG, C.E. 1936. Development and significance of the soil great groups of the United States. Washington: U.S. Gov. Print Office, 40 p.(USDA Misc. Publ., 229).

KELLOGG, C.E. 1948. Preliminary suggestions for the classification and nomenclature of great soil groups in tropical and subtropical regions. In: COMMONWEALTH BUREAU OF SOIL SCIENCE, Proceedings, 1: 78-85.

KERTZMAN, F.F. 1989. Modification de la structure et des proprietés des couches superficielles d'un "Latossolo Roxo" (Guaíra, São Paulo, Brésil) soumis à une irrigation par aspersion. Université. Paris VI, Paris, Travail de D.E.A., 48 p.

KING, L.C. 1956. A geomorfologia do Brasil Oriental. Revista Brasileira de Geomorfologia, 2: 147-263.

KLINGE, H. 1965. Podzol soils in the Amazon Basin. Journal of Soil Science, 16: 96-103.

KRUSEKOPF, H.H. 1925. The brown soils of the north central states. American Soil Survey Association Bulletin, 6: 146-148.

KUBIENA, W.L. 1952. Claves sistemáticas de suelos. Consejo Superior de Investigaciones Científicas, Madrid, 388 p.

LAATSCH, W. 1938. Dynamic der deutschen Acker und Waldböden 1. Aufl. Dresden, Leipzig, Steinkopff.

LADEIRA, F.S.B. 1995. Estudo micromorfológico de um Latossolo Roxo no município de Guaíra
- SP. Faculdade de Filosofia, Letras e Ciências Humanas, Universidade de São Paulo, São Paulo, Dissertação de Mestrado, 93p.

LEMOS, R.C. 1976. Os solos de eruptivas básicas do sul do Brasil. In: CONGRESSO BRASILEIRO DE CIÊNCIA DO SOLO, 15, Campinas, Anais, 351-358.

LEMOS, R.C.; SANTOS, R.D. 1976. Manual de Método de Trabalho de Campo. $4^{\mathrm{a}}$ impressão. Soc. Bras. Ciência do Solo, Campinas, 45p.

LEPRUN, J.C. 1977. Géochimie de la surface et formes de relief. IV. La dégradation des cuirasses ferrugineuses. Étude et importance du phénomène pédologique en Afrique de l'Ouest. Sciences Géologiques Bulletin, 30: 265-273.

LEPSCH, I.F.; BUOL, S.W. 1974. Investigations in an Oxisol-Ultisol toposequence in S. Paulo State, Brazil. Soil Science Society America Proceedings, 38: 491-496.

LEPSCH, I.F.; BUOL, S.W.; DANIELS, R.B. 1977. Soil-landscape relationships in the Occidental Plateau of São Paulo State, Brazil. II. Soil morphology, genesis, and classification. Soil Science Society of America Journal, 41: 109-115.

LIEBIG, J. 1840. Die Chemie in ihrer Andwendung auf Agrikultur und Physiologie. Vieweg und Söne. Braunschweig. (Chemistry and its applications to agriculture and physiology, apud Feller et al., 2003), 352 p.

LORANDI, R.; FREIRE, O.; ABRAHÃO, I.O.; MARCONI, A.; CLEMENTE, C.A. 1985. Areias Quarzosas da bacia do Ribeirão do Lobo (Brotas-Itirapina, SP). II. Características mineralógicas e químicas. Anais da Escola Superior de Agricultura Luiz de Queiroz, 42: 381-389.

LUEDER, D.R. 1959. Aerial photographic interpretation: principles and application. McGraw Hill, New York, 562p.

MAACK, R. 1950. Notas preliminares sobre clima, solos e vegetação do Paraná. Boletim Geográfico, 84: 1401-1487. Transcrições. (Tese do autor - Arquivos de Biologia e Tecnologia, v. III, 1948. Apresentada e aprovada na II Reunião Brasileira de Ciência do Solo, Campinas, 1949). 
MABESOONE, J.M. Ciclicidade e relevo. 2000. Revista Brasileira de Geomorfologia, 1: 68-72.

MABESOONE, J.M.; LOBO, H.R. 1980. Paleosols as stratigraphic indicators for the cenozoic history of Northeastern Brazil. Catena, 7: 67-78.

MARCONI, A. 1969. Contribuição ao estudo da mineralogia de solos do Município de Piracicaba. Escola Superior de Agricultura Luiz de Queiroz, Universidade de São Paulo, Piracicaba, Tese de Doutorado, $101 \mathrm{p}$.

MARCONI, A. 1973. Mineralogia de solos das Séries Anhumas, Cruz Alta e Ibitiruna. Anais da Escola Superior de Agricultura Luiz de Queiroz, 33: 415-428.

MARQUES, J.Q.A. 1958. (Coord.). Manual Brasileiro para Levantamentos Conservacionistas. Escritório Técnico de Agricultura Brasil-Estados Unidos, Rio de Janeiro.

MARTINS, G.M. 2007. Efeitos da ação de cupins sobre as propriedades de um perfil de solo em uma vertente da Represa Billings - São Bernardo do Campo/SP. Faculdade de Filosofia, Letras e Ciências Humanas, Universidade de São Paulo, São Paulo, Dissertação de Mestrado, 129p.

MELFI, A.J.; MONTES, C.R. 2008. Solo e Ambiente. In: R. Machado (ed.) As ciências da terra e sua importância para a humanidade. São Paulo, Soc. Bras. de Geologia, Livros Textos, 107-126.

MELFI, A.J; GIRARDI, V.A.; MONIZ, A.C. 1966. Mineralogia dos solos da Estação Experimental "Theodureto de Camargo" em Campinas. Bragantia, 25: 9-30.

MIKLÓS, A.A.W. 1992. Byodinamique d'une couverture pédologique dans la région de Botucatu, Brésil. Université Paris VII, Paris, Thèse de doctorat, $247 \mathrm{p}$.

MILLOT, G. 1977. Géochimie de la surface et formes du relief. Présentation. Sciences Géologiques Bulletin, 30: 229-233.

MILLOT, G. 1980. Les grands aplanissements des socles continentaux dans les pays subtopicaux, tropicaux et désertiques. Mémoire hors série de la Société Géologique de France, 10: 295- 305.
MILNE, G. 1935. Some suggested units of classification and mapping, particularly for east African soils. Soil Research, 4: 183-198.

MODENESI, M.C. 1980. Intemperismo e morfogênese no Planalto de Campos do Jordão (SP). Revista Brasileira de Geociências, 10: 213-225.

MODENESI, M.C.; SUGUIO, K.; COIMBRA, A.M. 1975. Provenance and reworking os ferralitic materials in the Itu region, State of São Paulo, Brazil. Anais da Academia Brasileira de Ciências, Suplemento, 47: 235-242.

MODENESI, M.C.; MATSUI, E.; VOLKOFF, B. 1982. Relação ${ }^{13} \mathrm{C} / 1^{2} \mathrm{C}$ nos horizontes humíferos dos solos de campo e mata na região de Campos do Jordão, São Paulo, Brasil. In: COLÓQUIO REGIONAL SOBRE MATÉRIA ORGÂNICA DO SOLO, Piracicaba, CENA/USP e Promocet, Anais, 155-160.

MOEYERSONS, J. 1981. Slumping and plannar sliding on hill-slopes in Rwanda. Earth Surface Processes and Landforms, 6: 265-274.

MOEYERSONS, J. 1987. The concentration of stones into a stone-line, as a result from sub-surface movements in fine and loose soils in the tropics. Geo-Eco-Trop, 11: 11-22.

MONIZ, A.C.; BUOL, S. 1982. Formation of an Oxisol-Ultisol transition in São Paulo, Brazil I. Double-matter flow model of soil development. Soil Science Society of America Journal, 46: 1228-1233.

MONIZ, A.C.; JACKSON, M.L. 1967. Quantitative mineralogical analysis of Brazilian soils derived from basic rocks and slate. Madison, University of Wisconsin, 74p. (Soil Science Report, 212).

MONIZ, A.C.; OLIVEIRA, J.B. 1974. Estudo mineralógico de solos derivados de rochas ígneas básicas da Estação Experimental de Ribeirão Preto, SP. In: CONGRESSO BRASILEIRO DE CIÊNCIA DO SOLO, 14, Santa Maria, Anais, 591-601.

MONIZ, A.C.; BUOL, S.W.; WEED, S.B. 1982. Formation of an Oxisol-Ultisol transition in São Paulo, Brazil. II. Lateral dynamics of chemical weathering. Soil Sci. Soc. Am. J., 46: 1234-1239. 
MORAES RÊGO, F.F. 1945. Considerações preliminares sobre a gênese e a distribuição dos solos do Estado de São Paulo. Boletim Geográfico (27): 351-356, IBGE, Conselho Nacional de Geografia. (Transcrito da revista Geografia, São Paulo, Ano I, 1935).

NETTLETON, W.D.; FLACH, K.W.; BRASHER, B.R. 1969. Argillic horizons without clay skins. Soil Sci. Soc. Amer. Proc., 33: 121-125.

NIKIFOROFF, C.C. 1949. Weathering and soil evolution. Soil Science: 67: 219-230.

NUNES, E.; ESPINDOLA, C.R. 1993. Morfologia, granulometria e química dos solos de superfícies terciárias do Rio Grande do Norte. Geociências, 12: 493-502.

OLIVEIRA, J.B.; MENK, J.R.F. 1984. Latossolos Roxo do Estado de São Paulo. Campinas: Instituto Agronômico, 132 p. (Boletim Técnico, 82).

OLIVEIRA, J.B.; PRADO, H. 1984. Levantamento pedológico do Estado de São Paulo - Quadrícula de São Carlos. II. Memorial Descritivo. Campinas, Instituto Agronômico (Boletim Informativo do Instituto Agronômico, 28).

OLIVEIRA, J.B.; ZANARDO, A.; NARDACHIONE, J.L. 1987. Morfoscopia, mineralogia e granulometria comparativa entre solos de uma mesma classe taxonômica situados em posições estratigráficas distintas. Geociências, 5/6: 59-78.

OLIVEIRA, J.B.; JACOMINE, P.K.; CAMARGO, M.N. 1992. Classes gerais de solos do Brasil - Guia auxiliar para seu reconhecimento. FUNEP, Jaboticabal, 201 p.

PAIVA NETTO, J.E.; CATANI, R.A.; KÜPPER, A.; MEDINA, H.P.; VERDADE, F.C.; GUTMANS, M.; NASCIMENTO, A.C. 1951. Observações gerais sobre os grandes tipos de solos do Estado de São Paulo. Bragantia, 11: 227-253.

PÉDRO, G.; VOLKOFF, B. 1984. Grandes provinces pédologiques du Brésil. Cadre générale de l'évolution pédologique. Cahiers ORSTOM, série Pédologie, 14: 169-188.

PÉDRO, G.; CHAUVEL, A.; QUEIROZ NETO, J.P.; MELFI, A.J. 1973. Contribuição ao co- nhecimento dos horizontes B das Terras Roxas Estruturadas. Aplicação dos métodos de análise granulométrica e da micromorfologia para a caracterização do seu tipo e organização. In: Soc. Bras. Ciência do Solo, CONGRESSO BRASILEIRO DE CIÊNCIA DO SOLO, 8, Vitória, 1971, Resumos, p. 120-121.

PÉDRO, G.; CHAUVEL, A.; MELFI, A.J. 1976. Recherches sur la constitution et la genèse des Terra Roxa Estruturada du Brésil. Annales Agronomiques, 27: 265-294.

PENCK, W. 1953. Morphological analysis of landforms: A contribution to physical geology. MacMillan \& Company, London, 429 p.

PENTEADO, M.M. 1976. Geomorfologia do Setor Centro-Ocidental da Depressão Periférica Paulista. São Paulo: Instituto de Geografia USP, 86p. (Série Teses e Monografias, 22).

PERECIN, D.; CAMPOS, D.A.F. 1976. Argila iluviada e gênese de Solos Podzolizados de Lins e Marília. In: Soc. Bras. Ciência do Solo, CONGRESSO BRASILEIRO DE CIÊNCIA DO SOLO, 15, Campinas, 1975, Anais, 467-473.

PESSENDA, L.C.R. 1991. Datação radiocarbônica de amostras de interesse arqueológico e geológico por espectrometria de cintilação líquida de baixa radiação de fundo. Química Nova, 14: 98-103.

PORTILHO, S.; ALMEIDA, M. 2008. O uso do infiltrômetro de disco em medidas de infiltração e percolação da água no solo em zona florestada, Parque das Mangabeiras, Belo Horizonte, MG. In: SIMPÓSIO NACIONAL DE GEOMORFOLOGIA, 7 e ENCONTRO LATINO AMERICANO DE GEOMORFOLOGIA, 2, Belo Horizonte, Resumos, p 169

QUEIROZ NETO, J.P. 1969. Interpretação dos solos da Serra de Santana para fins de classificação. Escola Superior de Agricultura Luiz de Queiroz, Universidade de São Paulo, Piracicaba, Tese de Doutorado, 135p.

QUEIROZ NETO, J.P. 1970. Étude sur le degré d'altération de quelques profis de sols de l'État de São Paulo-Brésil. Science du Sol, 2: 73-85.

QUEIROZ NETO, J.P. 1974. Proposição de uma tipologia dos materiais de origem dos solos do 
Brasil de Sudeste. Notícia Geomorfológica, 14: 77-94.

QUEIROZ NETO, J.P. 1976. Tendências atuais das pesquisas de solos em São Paulo. Boletim Paulista de Geografia, 50: 37-56.

QUEIROZ NETO, J.P. 2000. Geomorfologia e pedologia. Revista Brasileira de Geomorfologia, 1: 59-67.

QUEIROZ NETO, J.P. 2008. Relações entre as vertentes e os solos: uma revisão. In: UGB, SIMPÓSIO NACIONAL DE GEOMORFOLOGIA, 7, Belo Horizonte, Resumos, 179.

QUEIROZ NETO, J.P.; MODENESI, M.C. 1973. Observações preliminares sobre as relações entre os solos e a geomorfologia na área de Itu-Salto, Estado de São Paulo. São Paulo: Instituto de Geografia - USP, 28p.( Sedimentologia e Pedologia, 3).

QUEIROZ NETO, J.P.; ESPINDOLA, C.R.; GALHEGO, H.R. 1981. Considerações sobre as relações entre solos e relevo na Mantiqueira Norte Ocidental. Boletim Paulista de Geografia, 58: 65- 85 .

RAY, R.G. 1963. Fotografias aéreas na interpretação e mapeamento geológico. Instituto Geográfico e Geológico do Estado de São Paulo, São Paulo, 88 p.

RESENDE, M.; CURI, N.; SANTANA, D.P. 1988. Pedologia e Fertilidade do Solo - Interações e Aplicações. Brasília, Min. Educação/Lavras, Escola. Superior de Agricultura. de Lavras/ Piracicaba, Potafos, 81 p.

RIBEIRO, L.P. 1998. Os Latossolos Amarelos do Recôncavo Baiano - gênese, evolução e degradação. SEPLANTEC/CADCT, Salvador, $99 \mathrm{p}$.

RITTL, T.F.; COOPER, M. 2010. Ensino da relação solo-paisagem para alunos do Curso Técnico em Meio Ambiente. In: SIMPÓSIO BRASILEIRO DE EDUCAÇÃO EM SOLOS, 5, Curitiba, Resumos Expandidos, 182-183.

RUELLAN, F. 1950. Geomorfologia Geral. Boletim Geográfico, 84: 1522-1534.

RUELLAN, A. 1986. A história dos solos - alguns problemas de definição e interpretação. Geografia, 10: 183-191.
RUELLAN, A.; DOSSO, 1993. M. Regards sur le sol. Paris, Foucher, Universités Francophones, $192 \mathrm{p}$.

SAADI, A. 1993. Neotectônica da plataforma brasileira: esboço e interpretações preliminares. Geonomos, 1: 1-15.

SALAMUNI, E.; EBERT, A.D. 1997. A influência da neotectônica na implantação da drenagem atual na Bacia Sedimentar de Curitiba. In: CONGRESSO DA ASSOCIAÇÃO BRASILEIRA DE ESTUDOS DO QUATERNÁRIO, 6, Curitiba, Resumos Expandidos, p. 244-248.

SALLUN, A.E.M.; SUGUIO, K. 2007. Datação absoluta por termoluminescência do Alogrupo Alto Rio Paraná (SP, PR e MS). Revista do Instituto Geológico, 27- 28: 13-29.

SÁNCHEZ, P.A. 1985. Management of acid tropical soils for sustainable agriculture. International Board for Soil Research and Management - IBSRAM. (Proc 2), 299p.

SANTOS, L.J.C.; SALGADO, A.A.R.; RAKSA, M.L.; MARRENT, B.R. 2010. Gênese das linhas de pedra - Revisão de Literatura. Revista Brasileira de Geomorfologia, 11: 103-108.

SHAEFFER, C.E.R. 2001. Brazilian latosols and their B horizon microstructured as long-term biotic constructs. Aust. J. Soil Res., 39: 909-926.

SCHAETZL, R.J.; ANDERSON, S. 2005. Soil genesis and geomorphology. Cabridge Univ. Press, Cambridge, 817 p.

SHARPE, C.F.S. 1938. Landslides and related phenomena. Columbia Geomorphic Studies II. Columbia Univ. Press, New York, v. 15, 137 p.

SHAW, C.F. 1925. The development of soil profiles in southeastern Australia. American Soil Survey Association Bulletin, 6: 59-62.

SIMONSON, R.W. 1959. Modern concepts on soil genesis. Soil Science Society of America Proceedings, 23: 152-156.

SMALL, E.E.; ANDERSON, R.S.; HANCOCK, G.S. 1999. Estimates of the rate of regolith production using ${ }^{10} \mathrm{Be}$ and ${ }^{26} \mathrm{Al}$ from an alpine hillslope. Geomorphology, 27: 131-150.

SOARES, P.C.; LANDIM, P.M.B. 1976. Depósitos cenozóicos na região Centro Sul do Brasil. Notícia Geomorfológica, 16: 17-39. 
SOYER, J. 1972. Sédimentologie des sables terciaires de l'Entre-Sambre-et-Meuse Condrusien. Université de Louvain, Belgique, Thèse Doctorat, $488 \mathrm{p}$.

SUGUIO, K. Geologia Sedimentar. 2003. Edgard Blücher, São Paulo, 400 p.

TANDARICH, J.P.; DARMODY, R.G.; FOLLMER, L.R.; JOHNSON, D.L. 2002. Historical development of soil and weathering profile concepts from Europe to the United States of America. Soil Sci. Soc. Am. J., 66: 335-346.

TARDY, Y. Pétrologie dês latérites et des sols tropicaux. 1993. Masson, Paris, 459 p.

TATUMI, S.H.; GOZZI, G.; OLIVEIRA, V.I.; SALLUN, A.E.M. ; SUGUIO, K. 2006. Luminescence dating of quaternary deposits in geology in Brazil. Radiation Protection Dosimetry, 119: 462-469.

THOMAS, M.F. Geomorphology in the tropics. 1994. John Wiley and Sons, Chichester, $460 \mathrm{p}$.

THORNBURY, W.D. Principles of geomorphology. 1957. John Wiley and Sons, 3 ed, New York, $618 \mathrm{p}$.

TOLEDO, M.C.; OLIVEIRA, S.M.B.; MELFI, A.J. 2000. Intemperismo e formação do solo. In: W. Teixeira; M.C.M. Toledo; T.R. Fairchild; F. Taioli (Orgs.) Decifrando a Terra. São Paulo, Oficina de Textos, p. 139-166.

TOWNSEND, F.C.; REED, L.W. 1971. Effects of amorphous constituents of some mineralogical and chemical properties of a Panamenian Latosol. Clays and Clay Minerals, 19: 303-310.

TRICART, J. 1959. Informações para a interpretação paleogeográfica dos cascalheiros. Notícia Geomorfológica, 4: 1-11.

TRICART, J. 1968. As relações entre a morfogênese e a pedogênese. Notícia Geomorfológica, 8: 5-8.

TURENNE，J.F. 1977. Modes d'humification et differentiation podzolique dans deux toposéquences guyanaises. Paris: Université de Nancy, Paris, ORSTOM, 173 p. (Mémoires, 84).

UCHA, J.M.; VILAS BOAS, G.S.; HADLICH, G.M. 2010. O uso do radar de penetração no solo na investigação dos processos de transformação pedogeomorfológica. Revista Brasileira de Geomorfologia, 11: 85-96.

USA. 1994. Keys to Soil Taxonomy. Soil Conservation Service, Washington D.C.,.6 ed.

VAGELER, P. 1933. An introduction to tropical soils. Mac Millan, London, 240 p.

VAGELER, P. 1953. Princípios e métodos modernos do levantamento agrogeológico global em áreas grandes virgens. In: REUNIÃO BRASILEIRA DE CIÊNCIA DO SOLO, 4, Campinas, Anais, 275-283.

VAN DER VOORT, M. 1950. The lateritic soils of Indonesia. In: INTERNATONAL CONGRESS OF SOIL SCIENCE, 4, Amsterdam, Transactions, Groning, Hoitsema Brothers, 1: 277-281.

VAN VAMBEKE, A.R. 1967. Recent developments in the classification of the soils of the tropics. Soil Science, 104: 309-313.

VASCONCELOS, P.M.; ONOE, A.; KAWASHITA, K.; SOARES, A.J.; TEIXEIRA, W. 2002. ${ }^{40} \mathrm{Ar} /{ }^{39} \mathrm{Ar}$ geochronology at the Instituto de Geociências, USP: instrumentation, analytical procedures, and calibration. Anais da Academia Brasileira de Ciências, 74: 297-342.

VIDAL-TORRADO, P.; LEPSCH, I.F.; CASTRO, S.S. 2005. Conceitos e aplicações das relações pedologia-geomorfologia em regiões tropicais úmidas. In: Soc. Brasileira de Ciência do Solo, Tópicos em Ciência do Solo, 4: 145-192.

VILENSKI, D.G. 1937. Some regularities in the development of soil forming processes. Pedology, 6: 792-809.

VITEK, J.D. \& GIARDINO, J.R. 1993. Preface: A perspective on getting to the frontier. In: J.D. Vitek \& J.P. Giardino (eds.) Geomorphology: the research frontier and beyond. Elsevier, p. 1-12.

VITTE, A.C. 2001. Considerações sobre a teoria da etchplanação e sua aplicação nos estudos de formas de relevo nas regiões tropicais quentes e úmidas. Terra Livre, 16: 11-24.

VOLKOFF, B. 1984. Organisations régionales de la couverture pédologique du Brésil. 
Chronologie des différentiations. Cahiers ORSTOM, sér. Pédologie, 21: 225-236.

WASHBURNE, C.W. 1930. Petroleum geology of the State of São Paulo-Brazil. São Paulo: Comissão Geográfica e Geológica do Estado de São Paulo, 282 p. (Boletim, 22).

WAYLAND, E.J. 1933. Peneplains and some other erosional plattforms. Proctorate of Uganda
Geological Survey, Dept. of Minas, Annual Report Bulletin, Note 1: 77-79.

WOHLERS, A. 1964. Cenozóico. São Paulo: Instituto Geográfico e Geológico, Secretaria da Agricultura, p.147-164. (Boletim, 41).

ZONN, S.V. 1978. Modern views on Podzol and Pseudopodzol formation and their manifestation in soils. Soviet Soil Science, 10: $104-113$.

Endereço do autor:

Carlos Roberto Espindola - Programa de Pós-Graduação em Geografia do Instituto de Geociências da Universidade Estadual de Campinas - Cidade Universitária Zeferino Vaz - Distrito de Barão Geraldo, CEP 13083-970, Campinas, SP. E-mail: carlosespindola@uol.com.br 